OPEN ACCESS

Edited by:

Hannes Schmidt,

Universität Wien, Austria

Reviewed by:

Paul Hallett,

University of Aberdeen

United Kingdom

Lukas Van Zwieten, New South Wales Department of

Primary Industries, Australia

${ }^{*}$ Correspondence:

Vera L. Baumert vera.baumert@wzw.tum.de

Specialty section:

This article was submitted to Soil Processes,

a section of the journal

Frontiers in Environmental Science

Received: 03 September 2018 Accepted: 02 November 2018 Published: 27 November 2018

Citation:

Baumert VL, Vasilyeva NA, Vladimirov AA, Meier IC, Kögel-Knabner I and Mueller CW (2018) Root Exudates Induce Soil Macroaggregation Facilitated by Fungi in Subsoil. Front. Environ. Sci. 6:140. doi: 10.3389/fenvs.2018.00140

\section{Root Exudates Induce Soil Macroaggregation Facilitated by Fungi in Subsoil}

\author{
Vera L. Baumert ${ }^{1 *}$, Nadezda A. Vasilyeva ${ }^{2}$, Artem A. Vladimirov ${ }^{2,3}$, Ina C. Meier ${ }^{4}$, \\ Ingrid Kögel-Knabner ${ }^{1,5}$ and Carsten W. Mueller ${ }^{1}$
}

${ }^{1}$ Chair of Soil Science, Technical University of Munich, Freising, Germany, ${ }^{2}$ Interdisciplinary Laboratory for Mathematical Modeling of Soil Systems, V.V. Dokuchaev Soil Science Institute, Moscow, Russia, ${ }^{3}$ Bogoliubov Laboratory of Theoretical Physics, Joint Institute for Nuclear Research, Dubna, Russia, ${ }^{4}$ Plant Ecology, Albrecht-von-Haller Institute for Plant Sciences, University of Göttingen, Göttingen, Germany, ${ }^{5}$ Institute for Advanced Study, Technical University of Munich, Garching, Germany

Subsoils are known to harbor large amounts of soil organic carbon (SOC) and may represent key global carbon $(\mathrm{C})$ sinks given appropriate management. Although rhizodeposition is a major input pathway of organic matter to subsoils, little knowledge exists on $\mathrm{C}$ dynamics, particularly stabilization mechanisms, such as soil aggregation, in the rhizosphere of different soil depths. The aim of this study was to investigate the influence of natural and elevated root exudation on $\mathrm{C}$ allocation and aggregation in the topsoil and subsoil of a mature European beech (Fagus sylvatica L.) forest. We experimentally added model root exudates to soil at two different concentrations using artificial roots and analyzed how these affect SOC, nitrogen, microbial community composition, and size distribution of water-stable aggregates. Based on the experimental data, a mathematical model was developed to describe the spatial distribution of the formation of soil aggregates and their binding strength. Our results demonstrate that greater exudate additions affect the microbial community composition in favor of fungi which promote the formation of macroaggregates. This effect was most pronounced in the C-poor subsoil, where macroaggregation increased by $86 \%$ and SOC content by $10 \%$. Our modeling exercise reproduced the observed increase in subsoil SOC at high exudate additions. We conclude that elevated root exudation has the potential to increase biotic macroaggregation and thus the $\mathrm{C}$ sink strength in the rhizosphere of forest subsoils.

Keywords: soil organic carbon, soil depth, rhizosphere, aggregate fractionation, artificial roots, microbial community composition, aggregation model

\section{INTRODUCTION}

Soils represent the largest terrestrial organic carbon (OC) pool, thus, an increase in soil OC (SOC) stocks via improved management practices has the potential to mitigate global climate change (Jobbágy and Jackson, 2000; Lal et al., 2011; Powlson et al., 2011; Stockmann et al., 2013; Lal, 2016; Minasny et al., 2017). However, most studies on the carbon (C) sink strength of soils have focused on $\mathrm{C}$ dynamics in topsoils only. These usually harbor high OC concentrations, but are often very shallow, particularly in forest soils. In contrast, subsoils are characterized by low OC concentrations 
and a large volume. As a consequence of this large volume, subsoils store up to $70 \%$ of the global SOC stocks (Batjes, 1996; Jobbágy and Jackson, 2000).

Compared with the topsoil, the input of fresh organic matter $(\mathrm{OM})$ is scarce and more heterogeneous in deeper soil layers (Chabbi et al., 2009). A major input pathway of OC to subsoils is plant roots, which provide OM in the form of rhizodeposits such as dead root cells, soluble root exudates, sloughed-off cells, or mucilage (Rasse et al., 2005; Jones et al., 2009; Rumpel et al., 2012). These root-derived compounds trigger the development of a narrow zone around the roots, which is influenced by their activity and considered as a hotspot of biological, chemical, and physical activities in soils, i.e., the rhizosphere (Hinsinger et al., 2009). Rhizodeposits and especially soluble root exudates represent an easily available $\mathrm{C}$ source for soil microbes (van Hees et al., 2005) and have frequently been observed to alter the native C mineralization rates of inherent SOC (Huo et al., 2017), a process widely referred to as the priming effect (Kuzyakov, 2010; Dijkstra et al., 2013). This effect can be either positive or negative (i.e., accelerated or reduced decomposition of inherent SOM), and several studies have found that its magnitude may vary among soil types, soil depths (Paterson and Sim, 2013), and exudate addition rates (Blagodatskaya and Kuzyakov, 2008).

Plant roots and rhizodeposits as well as microorganisms in the rhizosphere promote soil aggregation (Amézketa, 1999) and thereby the occlusion of $\mathrm{OM}$ which is an important mechanism of C stabilization (Blanco-Canqui and Lal, 2004; von Lützow et al., 2006). In this regard, plant roots and fungi are of special importance for the formation of macroaggregates $(>250 \mu \mathrm{m})$ (Tisdall and Oades, 1982; Chantigny et al., 1997; Helfrich et al., 2008), whereas polysaccharides exuded by roots or microbes and $\mathrm{OM}$ in general may be relevant gluing agents for the formation of microaggregates (Amézketa, 1999; Totsche et al., 2018). Because soil aggregation is strongly influenced by biotic processes, it has long been considered less relevant in deeper, less biologically active soil horizons (Lorenz and Lal, 2005; von Lützow et al., 2006). Recently, evidence is growing that it is of similar importance for the stabilization of SOM in topsoils and subsoils (Rasmussen et al., 2005; Moni et al., 2010; Sanaullah et al., 2010; Rumpel et al., 2012). Because roots have been shown to play a significant role in the input and dynamics of OC in subsoils (Angst et al., 2016; Heinze et al., 2018), the question remains to what extent soluble root exudates drive the $\mathrm{C}$ allocation and soil aggregation in subsoil vs. topsoils.

By applying artificial root exudate mixtures as a surrogate for soluble rhizodeposits, their effects on soil processes can be examined. Most of the previous studies applying root exudates have focused mainly on biological parameters, such as soil respiration and microbial community structure and activity (Marx et al., 2010; Drake et al., 2013; Luo et al., 2014), and not on soil aggregation. Moreover, only few studies have investigated the effects of labile $\mathrm{C}$ additions to different soil depths so far, and if so, they were restricted to the determination of priming effects. Although the observed responses varied from an increased (Karhu et al., 2016) to a decreased (de Graaff et al., 2014) or even absent (Salomé et al., 2010) relative priming effect in deeper soil layers as compared with the topsoil, they agreed that subsoils appear to react differently to labile $\mathrm{C}$ additions than topsoils.

Currently, much uncertainty still exists regarding the mechanisms underlying SOM dynamics and rhizosphere processes in subsoils. In particular, their role as a source or sink of $\mathrm{CO}_{2}$ facing climate change and the mechanisms by which $\mathrm{C}$ is stored and protected in subsoils are largely unexplored (Rumpel and Kögel-Knabner, 2011). Knowledge regarding these processes, particularly including the influence on aggregation as a way to stabilize SOC, is urgently needed to improve the modeling of SOC cycling and to assess the role of subsoils in soil C dynamics.

For the study and prediction of SOC dynamics, mathematical models that are based on processes involved in $\mathrm{C}$ cycling are of high importance (Campbell and Paustian, 2015). Although it is known that aggregation plays an important role in SOC stabilization, it is rarely considered in current soil biogeochemical models (Abramoff et al., 2017). Abramoff et al. (2017) recently made an attempt to include $\mathrm{C}$ storage within aggregates in their conceptual model, but concluded that the lack of robust data on aggregate turnover made soil aggregation the model's most uncertain component. Mathematical models that simulate the process of soil aggregation itself and could be implemented in general SOM models are especially scarce to date. Albalasmeh and Ghezzehei (2014) modeled soil structure development under consideration of root exudation and soil moisture, but did not consider soil microbes nor link aggregation to SOC storage. Several studies modeled soil aggregate formation based on the conceptual model that macroaggregates form around particulate OM and release microaggregates upon disruption (Oades, 1984): Segoli et al. (2013) thereby accounted for the effects of microbial activity on macroaggregate formation and integrated it in SOM dynamics, while Stamati et al. (2013) linked aggregate turnover with different conceptual SOC pools, among them microbial biomass. Still, there is a lack of modeling approaches addressing soil aggregation processes in the rhizosphere as a protection mechanism for SOC. Especially the effect of soil moisture on microbial abundance and the influence of both parameters on soil structure formation needs to be further addressed (Crawford et al., 2012; Vasilyeva et al., 2016; Banwart et al., 2017).

In the present study, we combined experimental approaches and mathematical modeling in order to investigate the effect of artificial root exudates on SOC content, and aggregate formation under consideration of the microbial community structure in topsoil and subsoil. To do so, we inserted artificial roots (Kuzyakov et al., 2006; Keiluweit et al., 2015; Meier et al., 2017) in microcosms repacked with soil material from different depths and used them to inject root exudates. Varying addition rates of labile $\mathrm{C}$ have been found to affect the decomposition of inherent SOM (Blagodatskaya and Kuzyakov, 2008) as well as activities of enzymes that degrade fast-cycling nitrogen $(\mathrm{N})$ pools nonlinearly (Meier et al., 2017). Thus, we aimed to assess the effect of different quantities of exudate amendments. One of our exudate addition treatments simulated natural $\mathrm{C}$ concentrations of root exudation in temperate acidic beech forests (Meier, personal communication), whereas the other one was an experimentally increased exudate concentration that has been applied in several 
similar experiments (Keiluweit et al., 2015; Meier et al., 2017). The aggregate formation model presented in this study uses a novel approach by modeling spatial gradients of microbial abundance, moisture, and gluing agents around the exuding root. This defines patterns of binding strength between soil particles and finally simulates aggregate size distribution.

In our laboratory experiment, we are not aiming at completely simulating natural conditions such as subsoil specific temperature and aeration or mycorrhizal symbiosis. Despite these limitations, our well-defined model system enabled us to experimentally simulate the local formation of rhizosphere properties under controlled conditions and to study the processes involved. Based on these experimentally measured variables, we propose a new approach to model aggregate formation driven by microbial SOM transformations and soil moisture due to the release of varying rates of soluble root exudates within the rhizosphere.

\section{MATERIALS AND METHODS}

\section{Study Site and Soil Sampling}

Soil samples were taken in March 2017 in an even aged forest dominated by European beech (Fagus sylvatica L.) near Rüdershausen, Lower Saxony, Germany ( $51^{\circ} 34^{\prime} 51.52^{\prime \prime} \mathrm{N}, 10^{\circ}$ $\left.14^{\prime} 43.03^{\prime \prime} \mathrm{O}\right)$. The study site is located at $200 \mathrm{~m}$ a.s.l., and is characterized by a mean annual temperature of $9.2^{\circ} \mathrm{C}$ and mean annual precipitation of $650 \mathrm{~mm}$ (Deutscher Wetterdienst, Station Goettingen). The soil developed on quaternary loess deposits was classified as a Haplic Cambisol (IUSS Working Group WRB, 2015) (Ol/Ah/Bw/Bwg1/Bwg2). The soil material used for the laboratory incubation was sampled from one soil profile at two horizons: the uppermost mineral horizon (Ah, 0$5 \mathrm{~cm}$ ) is subsequently referred to as topsoil, and the Bwg1 horizon $(33-50 \mathrm{~cm})$ is referred to as subsoil. After sieving of the soil materials $<2 \mathrm{~mm}$, the remaining root and litter fragments were removed manually by picking with tweezers. Until the start of the incubation experiment, the soils were stored field-moist at $4^{\circ} \mathrm{C}$. Table 1 lists soil texture and other basic soil properties of the top and subsoil materials used for the incubation experiment.

\section{Experimental Setup}

Square Petri dishes prepared with a cut-out for the artificial root and aeration holes were used as microcosms. They were packed with soil at field bulk density $\left(1.06 \mathrm{~g} \mathrm{~cm}^{-3}\right.$ for topsoil and $1.40 \mathrm{~g} \mathrm{~cm}^{-3}$ for subsoil) and $60 \%$ water holding capacity (WHC). Rhizon soil moisture samplers (Rhizosphere Research Products, Wageningen, Netherlands) were completely inserted in the center of the microcosm during the packing process to ensure tight soil contact. Rhizon samplers are microporous capillaries $(9.3 \mathrm{~cm}$ length, $2.5 \mathrm{~mm}$ outer diameter, mean pore size of $0.15 \mu \mathrm{m}$ ), which served as artificial roots (Figure S1). The tubing of the Rhizon sampler was sealed using a back-pressure valve (Infuvalve ${ }^{\circledR}$, BBraun, Melsungen, Germany) to prevent air from entering the system.

After a preincubation period of 7 days, the artificial roots were supplied with $0.5 \mathrm{ml}$ of model exudate solution twice per day over the course of 30 days at $20^{\circ} \mathrm{C}$ (at atmospheric
TABLE 1 | Basic soil properties of the soil material used for incubation (before incubation).

\begin{tabular}{|c|c|c|}
\hline & Topsoil & Subsoil \\
\hline $\mathrm{OC}\left(\mathrm{mg} \mathrm{g}^{-1}\right)$ & 33.31 & 3.26 \\
\hline $\mathrm{N}\left(\mathrm{mg} \mathrm{g}^{-1}\right)$ & 2.31 & 0.41 \\
\hline $\mathrm{C} / \mathrm{N}$ ratio & 14.44 & 7.97 \\
\hline \multicolumn{3}{|l|}{ TEXTURE (\%) } \\
\hline Medium and coarse sand (>250 $\mu \mathrm{m})$ & 0.7 & 0.4 \\
\hline Fine sand (>53 $\mu \mathrm{m})$ & 9.2 & 6.0 \\
\hline Silt (53-2 $\mu \mathrm{m})$ & 64.0 & 67.2 \\
\hline Clay $(<2 \mu \mathrm{m})$ & 26.2 & 26.4 \\
\hline Total PLFA content (nmol g ${ }^{-1}$ ) & 133.7 & 4.4 \\
\hline$F: B P L F A$ & 0.4 & 0.3 \\
\hline Total AS content ( $\mu \mathrm{g}$ AS C $\mathrm{g}^{-1} \mathrm{SOC}$ ) & 26.2 & 46.1 \\
\hline $\mathrm{F}: \mathrm{B}_{\mathrm{AS}}$ & 1.7 & 2.3 \\
\hline \multicolumn{3}{|c|}{ AGGREGATE SIZE CLASS DISTRIBUTION (\%) } \\
\hline$>250 \mu \mathrm{m}$ & 52 & 24 \\
\hline $250-53 \mu \mathrm{m}$ & 36 & 58 \\
\hline 53-20 $\mu \mathrm{m}$ & 9 & 13 \\
\hline$<20 \mu \mathrm{m}$ & 4 & 4 \\
\hline \multicolumn{3}{|l|}{$O C\left(\mathrm{mg} \mathrm{g}^{-1}\right)$} \\
\hline$>250 \mu \mathrm{m}$ & 41.9 & 4.5 \\
\hline $250-53 \mu \mathrm{m}$ & 28.9 & 3.1 \\
\hline 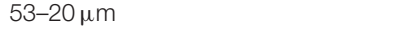 & 14.1 & 2.6 \\
\hline$<20 \mu \mathrm{m}$ & 16.1 & 6.6 \\
\hline DOC & 0.6 & 0.5 \\
\hline \multicolumn{3}{|l|}{$N\left(\mathrm{mg} \mathrm{g}^{-1}\right)$} \\
\hline$>250 \mu \mathrm{m}$ & 2.7 & 0.4 \\
\hline $250-53 \mu \mathrm{m}$ & 2.0 & 0.4 \\
\hline 53-20 $\mu \mathrm{m}$ & 1.1 & 0.3 \\
\hline$<20 \mu \mathrm{m}$ & 1.6 & 0.8 \\
\hline $\mathrm{dNt}$ & 0.1 & 0.1 \\
\hline \multicolumn{3}{|l|}{$\mathrm{C} / \mathrm{N}$} \\
\hline$>250 \mu \mathrm{m}$ & 15.5 & 11.3 \\
\hline $250-53 \mu \mathrm{m}$ & 14.5 & 7.8 \\
\hline $53-20 \mu \mathrm{m}$ & 12.8 & 8.7 \\
\hline$<20 \mu \mathrm{m}$ & 10.1 & 8.3 \\
\hline DOM & 4.6 & 9.0 \\
\hline
\end{tabular}

oxygen levels). The artificial exudate solution contained $60 \%$ acetic acid, 35\% glucose, and 5\% serine. These compounds were selected based on the reported exudate chemistry of trees (Smith, 1970, 1976; Shen et al., 1996), and the specific contents correspond to the relative proportions of organic acids, simple sugars, and amino acids, respectively, as exuded by mature trees (Smith, 1976). The respective concentrations of the exudate solutions for the treatments were set to 0,6 , and $180 \mu \mathrm{g} \mathrm{C} \mathrm{cm}{ }^{-2}$ root surface $\mathrm{d}^{-1}$ and are subsequently referred to as "water control," "moderate," and "high." The water control samples received only deionized water, whereas the moderate treatment represents realistic C-based exudation rates for European beech trees (Brzostek et al., 2012; Tückmantel et al., 2017). The amount used in the high treatment was 
chosen with reference to previous experiments with artificial root exudates that used such high concentrations (Keiluweit et al., 2015; Meier et al., 2017). The solutions were injected manually with a syringe, having a syringe filter attached for sterile filtration $(0.22 \mu \mathrm{m})$ (Figure S1). Fresh exudate solutions were prepared weekly and stored at $4^{\circ} \mathrm{C}$. Each treatment was run in four replicates. During the incubation period, soil moisture content was regularly checked and maintained at $60 \%$ WHC by adding small amounts of deionized water through the aeration holes of the microcosms. The addition rate of $1 \mathrm{ml}$ exudate solution per day and microcosm almost equaled the daily amount of evaporation so that nearly no additional water had to be provided to the microcosms in order to hold constant moisture.

After an incubation period of 30 days, soil within a radius of $6 \mathrm{~mm}$ around the artificial roots which was assumed to be directly influenced by the exudate solution (Drake et al., 2013), was sampled as the artificial rhizosphere (subsequently referred to as rhizosphere) and the remaining material ( $>6 \mathrm{~mm}$ from the Rhizon sampler) as the bulk soil. Normalized to the mass of the rhizosphere soil, moderate exudate additions amounted to 2.8 and $2.1 \mu \mathrm{g} \mathrm{C} \mathrm{g}^{-} 1$ dry soil $\mathrm{d}^{-1}$ and those of the high treatment to 83.9 and $63.7 \mu \mathrm{g} \mathrm{C} \mathrm{g}^{-} 1$ dry soil $\mathrm{d}^{-1}$ in topsoil and subsoil, respectively. Aliquots of the sampled soil material were stored air-dried and freeze-dried, respectively, for subsequent analyses.

\section{Phospholipid Fatty Acid Analysis}

Phospholipid fatty acids (PLFA) were extracted following the method described by Frostegård et al. (1991) with modifications by Kramer et al. (2013). Approximately $2 \mathrm{~g}$ of topsoil and $7 \mathrm{~g}$ of subsoil (freeze-dried aliquot) were treated with Bligh \& Dyer solution [methanol, chloroform, citrate buffer $(\mathrm{pH}=$ 4), 2:1:0.8, v/v/v] to extract the lipids. The PLFA fraction was separated by solid phase extraction on silica columns $(0.5 \mathrm{~g}$ $\mathrm{SiOH}$, Chromabond ${ }^{\circledR}$, Macherey-Nagel, Düren, Germany) and transformed into fatty acid methyl esters (FAMEs) by alkaline methanolysis. The dried extracts were dissolved in isooctane and determined using a Trace 1300 gas chromatograph (Thermo Fisher Scientific, Waltham, MA, USA) with flame ionization detection (GC-FID) using a ZB-5HT fused silica capillary column (60 m, 0.25 I.D., $0.25 \mu \mathrm{m}$ film thickness; Phenomenex Ltd., Aschaffenburg, Germany). The PLFA concentrations were quantified relative to non-adecanoic acid methyl ester (19:0) as internal standard and subsequently normalized to the mean longterm results of a standard soil that was extracted parallel in order to level differences between single extractions.

The PLFAs were categorized into groups indicative of bacteria (i15:0, a15:0, i16:0, i17:0, cy17:0, cy19:0, 15:0, 16:1n7, and 17:0) and fungi (18:2n6 and 18:1n9). Although it is also present in bacteria and plants in minor contents, 18:1n9 has been shown to be a reliable indicator for fungi in forest soils (Kaiser et al., 2010; Frostegård et al., 2011). All the above mentioned fatty acids together with 14:0, 16:0, 18:1n9, 18:1n9t, 18:0, and 20:0 were used for the calculation of total microbial PLFAs. The total microbial PLFA content is used as an indicator for changes in microbial biomass (Frostegård et al., 1991; Bailey et al., 2002). Several other PLFAs were detected in the samples, which could be of microbial origin as well. However, only PLFA peaks that were identified unambiguously via mass spectrometry in pre-experiments were selected as biomarkers. Therefore, PLFA extracts from test samples as well as qualitative standard mixtures (37-Component FAME Mix and Bacterial Acid Methyl Esters Mix; Supelco, Bellefonte, PA, USA) were measured on a Trace GC Ultra coupled to an ISQ mass spectrometer (Thermo Fisher Scientific) using the same capillary column and temperature program that was used for GC-FID analysis. A PLFA-based fungal-to-bacterial-ratio (F:B $B_{\text {PLFA }}$ ) was calculated from the PLFA contents of the fungal PLFA and total bacterial PLFAs.

\section{Amino Sugar Analysis}

The amino sugars (AS) glucosamine (GluN), mannosamine (ManN), galactosamine (GalN), and muramic acid (MurA) were extracted from rhizosphere and bulk soil samples according to Zhang and Amelung (1996). Freeze-dried aliquots of the samples were ground and hydrolyzed with $6 \mathrm{M} \mathrm{HCl}$ at $105^{\circ} \mathrm{C}$ for $8 \mathrm{~h}$. Subsequently, the extracts were filtered and neutralized to separate impurities by precipitation and derivatized to form aldonitrile acetates. The dried extracts were redissolved in ethyl acetate:hexane $(1: 1 ; \mathrm{v} / \mathrm{v})$ before measurement on a Trace 1300 gas chromatograph (Thermo Fisher Scientific) equipped with a ZB-5HT fused silica capillary column (60 m, 0.25 I.D., $0.25 \mu \mathrm{m}$ film thickness; Phenomenex LTD, Aschaffenburg, Germany) and a flame ionization detector. The internal standard myoinositol was used as a reference to quantify AS concentrations.

The total AS content was calculated per sample as the sum of the four AS. Following Van Groenigen et al. (2007), the bacterialand fungal-derived AS C was calculated and used to obtain an estimate of the AS-based fungal-to-bacterial ratio ( $\left.F: B_{A S}\right)$.

\section{Aggregate Fractionation}

The rhizosphere and bulk soil samples were fractionated by wet sieving, yielding different size classes of water-stable aggregates (Puget et al., 1999). Therefore, $5 \mathrm{~g}$ of air-dried sample material was rewetted in deionized water for $30 \mathrm{~min}$, transferred to a sieve tower $(250,53$, and $20 \mu \mathrm{m}$ stainless steel sieves, $100 \mathrm{~mm}$ diameter), and placed in a beaker with deionized water. The sieve tower was moved up and down through a vertical distance of $2 \mathrm{~cm}$ at 30 cycles per minute for $5 \mathrm{~min}$. The single fractions were washed from the sieves and freeze-dried. Fractions $<20 \mu \mathrm{m}$ that remained in the beaker were filtered at $0.45 \mu \mathrm{m}$ in a pressure filtration unit, washed off from the filter, and freeze-dried as well. This method resulted in the following four aggregate fractions: $>250 \mu \mathrm{m}$ (macroaggregates), $250-53,53-20$, and $<20 \mu \mathrm{m}$. The average recovery rate of the aggregate fractionation procedure was $98.8 \%$ of the initial soil mass for samples from either depth. Additionally, the filtrate was analyzed for dissolved OC (DOC) and dissolved total $\mathrm{N}(\mathrm{dNt})$ on a total $\mathrm{C}$ analyzer coupled to a total bound $\mathrm{N}\left(\mathrm{TN}_{\mathrm{b}}\right)$ module (DIMATOC 2000 and DIMA-N; Dimatec Analysentechnik GmbH, Essen, Germany).

\section{Carbon and Nitrogen Measurements}

$\mathrm{C}$ and nitrogen $(\mathrm{N})$ contents of the rhizosphere and the bulk soil, and the aggregate size fractions, were analyzed by dry combustion using an elemental analyzer (Eurovector, Milan, Italy). AR, bulk soil, and fractions $>53 \mu \mathrm{m}$ were finely ground in a ball mill before 
the analysis. All measurements were performed in duplicate. Because the soils did not contain carbonates, total $\mathrm{C}$ contents were considered to be equal to OC contents.

\section{Mathematical Modeling}

The introduced model comprisesof two parts: The first one is a biochemical cycle that describes exudate diffusion in water, followed by local OM transformations, microbial growth, and turnover, resulting in the formation of gluing agents that provide a mechanism of aggregation (Figure 1). Spatial patterns of these model variables are generated up to a distance of $12 \mathrm{~mm}$ from the artificial root. The second part is an aggregation model that describes how the distribution of water-stable aggregate size classes is obtained from the spatial patterns of gluing agents and fungi. All model parameter estimates are listed in Table 2.

\section{Modeling of Rhizosphere Patterns}

The evolution of spatial patterns of the biochemical cycle (Figure 1) was modeled by a system of partial differential equations solved in $2 \mathrm{D}$ using cylindrical coordinates (Equation 1). The model variables are: bacterial biomass (B), root exudates (E), gluing agents $(\mathrm{G})$, fungal biomass $(\mathrm{F})$, and SOM (S). All concentrations in the model are expressed in $\mathrm{g} \mathrm{C}$ $\mathrm{cm}^{-3}$ soil using soil bulk densities. Water saturation $(\theta)$ affects all rates of biological processes by a moisture factor $\mathrm{W}=\theta-\theta_{0}$, where $\theta_{0}$ is the minimal saturation for biological processes.

$$
\frac{\partial \mathbf{u}}{\partial \mathrm{t}}=\frac{1}{\mathrm{r}} \frac{\partial}{\partial r}\left(r \mathbf{D}(u) \frac{\partial \mathbf{u}}{\partial \mathrm{r}}\right)+\frac{\partial}{\partial \mathrm{z}}\left(\mathbf{D}(\mathbf{u}) \frac{\partial \mathbf{u}}{\partial \mathrm{z}}\right)+\boldsymbol{\phi}(\mathbf{u}),
$$

where $\mathbf{u}(\mathrm{r}, \mathrm{z}) \equiv(\mathrm{B}, \mathrm{F}, \mathrm{E}, \mathrm{G}, \mathrm{S}, \theta)$ is the vector of volumetric concentrations of the state variables of the system measured in

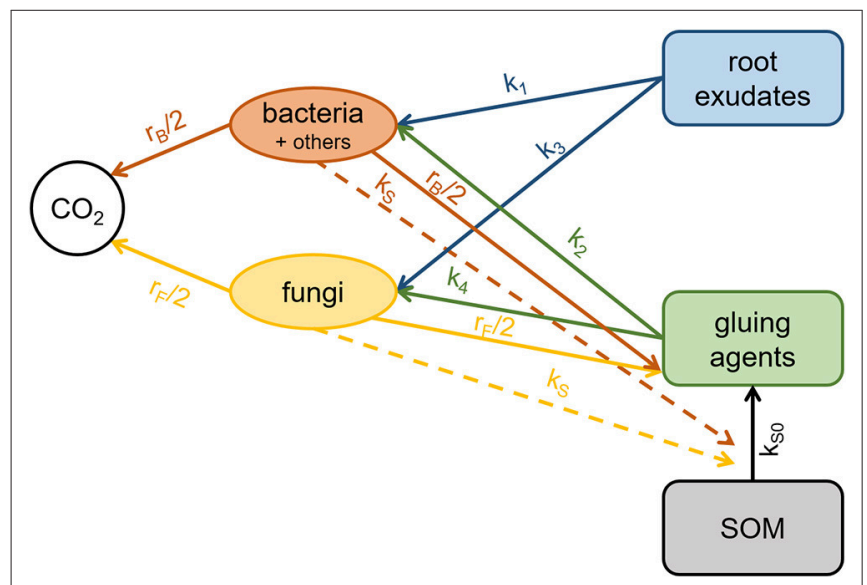

FIGURE 1 | Scheme of the biochemical cycle underlying the mathematical model, where solid arrows represent $\mathrm{C}$ transfer rates and dashed arrows catalytic effects. $\left[\mathrm{g} \mathrm{cm}^{-3}\right]$ and $\phi(\mathbf{u})$ is the reaction part and defined as:

$$
\begin{aligned}
\phi_{\mathrm{B}} & =\left(\mathrm{T}_{\mathrm{EB}}+\mathrm{T}_{\mathrm{GB}}\right)\left(1-\mathrm{B} / \mathrm{m}_{1}\right)-\mathrm{r}_{\mathrm{B}} \mathrm{B}, \\
\phi_{\mathrm{F}} & =\left(\mathrm{T}_{\mathrm{EF}}+\mathrm{T}_{\mathrm{GF}}\right)\left(1-\mathrm{F} / \mathrm{m}_{1}\right)-\mathrm{r}_{\mathrm{F}} \mathrm{F}, \\
\phi_{\mathrm{E}} & =-\mathrm{T}_{\mathrm{EB}}-\mathrm{T}_{\mathrm{EF}}, \\
\phi_{\mathrm{G}} & =-\mathrm{T}_{\mathrm{GB}}-\mathrm{T}_{\mathrm{GF}}+\mathrm{T}_{\mathrm{SG}}+\mathrm{r}_{\mathrm{B}} \mathrm{B} / 2+\mathrm{r}_{\mathrm{F}} \mathrm{F} / 2, \\
\phi_{\mathrm{S}} & =-\mathrm{T}_{\mathrm{SG}}, \\
\phi_{\boldsymbol{\theta}} & =-\mathrm{d}_{\theta} \theta
\end{aligned}
$$

where $\mathrm{T}_{\mathrm{ij}}$ denotes the $\mathrm{C}$ transfer rate from pool $\mathrm{i}$ to pool $\mathrm{j}$, and $\mathrm{d}_{\theta}$ is a constant evaporation rate fitted under the assumption that average moisture was kept constant during the incubation experiment. The decline in carbon use efficiency (CUE) with growing biomass is introduced by $\mathrm{m}_{1}$ which reflects the environmental capacity for microbes. At this maximum of microbial biomass, microbes are supposed to stop growth but continue respiration and thus reach minimal CUE.

Carbon transfer rates describe the bacterial and fungal growth on root exudates $\left(\mathrm{T}_{\mathrm{EB}}, \mathrm{T}_{\mathrm{EF}}\right)$ and gluing agents $\left(\mathrm{T}_{\mathrm{GB}}, \mathrm{T}_{\mathrm{GF}}\right)$ and enzymatic (proportional to $\mathrm{B}$ and $\mathrm{F}$ ) as well as abiotic breakdown of SOM into the pool of gluing agents $\left(\mathrm{T}_{\mathrm{SG}}\right)$ according to the model scheme shown in Figure 1:

$$
\begin{aligned}
\mathrm{T}_{\mathrm{EB}} & =\mathrm{k}_{1} \mathrm{EBW}, \\
\mathrm{T}_{\mathrm{EF}} & =\mathrm{k}_{3} \mathrm{EFW}, \\
\mathrm{T}_{\mathrm{GB}} & =\mathrm{k}_{2} \mathrm{GBW}\left(1-\mathrm{B} / \mathrm{m}_{1}\right), \\
\mathrm{T}_{\mathrm{GF}} & =\mathrm{k}_{4} \mathrm{GFW}\left(1-\mathrm{F} / \mathrm{m}_{1}\right), \\
\mathrm{T}_{\mathrm{SG}} & =\mathrm{k}_{\mathrm{S}}\left(\mathrm{B}+\mathrm{F}+\mathrm{k}_{\mathrm{S} 0}\right) \mathrm{SW},
\end{aligned}
$$

where $k_{1}, k_{2}, k_{3}$, and $k_{4}$ are substrate consumption rates by microbes.

Considering community-level regulated processes that are introduced using density-dependence (Georgiou et al., 2017), we formulate a gradual change in substrate preference in favor of root exudates, which are assumed to be the more easily degradable substrate. In the model we expect that the concentration of organic gluing agents increases with the $\mathrm{C}$ concentration of the added exudates. Because, the production is expected to increase due to higher microbial biomass and subsequent enzymatic breakdown of SOM, the consumption is expected to decrease due to microbial substrate preference at high biomass. The latter is described by the factors (1 $\left.\mathrm{B} / \mathrm{m}_{1}\right)$ and $\left(1-\mathrm{F} / \mathrm{m}_{1}\right)$ and introduces the possibility of both positive and negative priming effects (Kuzyakov et al., 2000). The transformation of SOM to gluing agents $\left(T_{S G}\right)$ is controlled by the enzymatic breakdown rate $\mathrm{k}_{\mathrm{S}}$ and the abiotic breakdown rate $\mathrm{k}_{\mathrm{S} 0}$. Microbial decay rates $\left(\mathrm{r}_{\mathrm{B}}\right.$ and $\mathrm{r}_{\mathrm{F}}$ ) are also assumed to be densitydependent (Georgiou et al., 2017), slowing down to dormant biomass threshold $\mathrm{m}_{0}$ at low biomass and increasing until $\mathrm{m}_{1}$ at high biomass.

$$
\begin{aligned}
& \mathrm{r}_{\mathrm{B}}=\mathrm{k}_{\mathrm{rb}} \theta\left(1-\mathrm{m}_{0} / \mathrm{B}\right) /\left(1-\mathrm{B} / \mathrm{m}_{1}\right) \\
& \mathrm{r}_{\mathrm{F}}=\mathrm{k}_{\mathrm{rf}} \theta\left(1-\mathrm{m}_{0} / \mathrm{F}\right) /\left(1-\mathrm{F} / \mathrm{m}_{1}\right),
\end{aligned}
$$

where $\mathrm{k}_{\mathrm{rb}}$ and $\mathrm{k}_{\mathrm{rf}}$ are the decay constants for bacteria and fungi, correspondingly. 
TABLE 2 | Model parameter estimates.

\begin{tabular}{|c|c|c|c|}
\hline Parameter & Description & Topsoil & Subsoil \\
\hline$\theta_{0}$ & Minimal saturation for biological processes & 0.2 & 0.2 \\
\hline$d_{\theta}$ & Constant evaporation rate & $9 \times 10-5 s-1$ & $9 \times 10-5 s-1$ \\
\hline$D_{E}$ & Diffusion constant of root exudates & $5.33 \times 10^{-7} \mathrm{~mm}^{2} \mathrm{~s}^{-1}$ & $5.33 \times 10^{-7} \mathrm{~mm}^{2} \mathrm{~s}^{-1}$ \\
\hline$D_{\theta}$ & Diffusion constant of water & $1.07 \times 10^{-6} \mathrm{~mm}^{2} \mathrm{~s}^{-1}$ & $1.07 \times 10^{-6} \mathrm{~mm}^{2} \mathrm{~s}^{-1}$ \\
\hline $\mathrm{k}_{1}$ & Substrate consumption rate & $0.047 s^{-1}$ & $0.037 s^{-1}$ \\
\hline $\mathrm{k}_{2}$ & Substrate consumption rate & $0.021 \mathrm{~s}^{-1}$ & $0.018 s^{-1}$ \\
\hline$k_{3}$ & Substrate consumption rate & $0.0504 \mathrm{~s}^{-1}$ & $0.0055 s^{-1}$ \\
\hline $\mathrm{k}_{4}$ & Substrate consumption rate & $0.0035 \mathrm{~s}^{-1}$ & $0.0030 \mathrm{~s}^{-1}$ \\
\hline $\mathrm{k}_{\mathrm{S}}$ & Enzymatic breakdown rate & $7.02 \times 10^{-5} \mathrm{~s}^{-1}$ & $3.13 \times 10^{-5} \mathrm{~s}^{-1}$ \\
\hline $\mathrm{k}_{\mathrm{SO}}$ & Abiotic breakdown rate & $1.26 \times 10^{-4} \mathrm{~g} \mathrm{~g}^{-1}$ & 0 \\
\hline $\mathrm{k}_{\mathrm{rb}}$ & Decay constant bacteria & $3.5 \times 10^{-7} \mathrm{~s}^{-1}$ & $8.4 \times 10^{-7} \mathrm{~s}^{-1}$ \\
\hline$k_{\text {rf }}$ & Decay constant fungi & $5.6 \times 10^{-7} \mathrm{~s}^{-1}$ & $8.4 \times 10^{-7} \mathrm{~s}^{-1}$ \\
\hline $\mathrm{m}_{0}$ & Dormant biomass threshold & $3.2 \times 10^{-5} \mathrm{~g} \mathrm{~g}^{-1}$ & $2.2 \times 10^{-6} \mathrm{~g} \mathrm{~g}^{-1}$ \\
\hline$m_{1}$ & Maximum biomass & $6.4 \times 10^{-4} \mathrm{~g} \mathrm{~g}^{-1}$ & $4.5 \times 10^{-5} \mathrm{~g} \mathrm{~g}^{-1}$ \\
\hline $\mathrm{p}_{0}$ & Mean disruptive force & $10.2 \mathrm{~mm}^{-1}$ & $11.8 \mathrm{~mm}^{-1}$ \\
\hline$v_{1}$ & Coefficient of gluing agents effect on binding strength & $578 \mathrm{~cm}^{3} \mathrm{~g}^{-1}$ & $820 \mathrm{~cm}^{3} \mathrm{~g}^{-1}$ \\
\hline$v_{2}$ & Coefficient of fungi effect on binding strength & $2.89 \times 10^{3} \mathrm{~cm}^{3} \mathrm{~g}^{-1}$ & $4.1 \times 10^{3} \mathrm{~cm}^{3} \mathrm{~g}^{-1}$ \\
\hline$\theta_{\mathrm{a}}$ & Coefficient of moisture effect on binding strength & 0.5 & 2.8 \\
\hline
\end{tabular}

The moisture-dependent diffusion of water and exudate was calculated as

$$
\mathbf{D}(\mathbf{u})=\mathbf{D}_{0}(\mathbf{u})\left(0.75+\theta^{2}\right),
$$

where $\mathbf{D}_{0}$ is a vector of diffusion constants. Cylindrical model parameters correspond to the experimental setup geometry and include the root radius $\left(\mathrm{r}_{0}=1.25 \mathrm{~mm}\right)$, microcosm width $\left(\mathrm{r}_{1}\right.$ $=13.25 \mathrm{~mm})$, and microcosm height $\left(\mathrm{z}_{1}=93 \mathrm{~mm}\right)$. Thus, model boundary conditions comprise no fluxes through the upper and lower surfaces of the sample cylinder, no fluxes through the side cylindric surface, and no fluxes from the root surface, except for exudate and water, which have a constant value at the root surface:

$$
\begin{aligned}
\frac{\partial \mathbf{u}}{\partial \mathrm{z}} & =\left.0\right|_{\mathrm{z}=0, \mathrm{z}=\mathrm{z}_{1}} \\
\frac{\partial \mathbf{u}}{\partial \mathrm{r}} & =\left.0\right|_{r=r_{1}} \\
\frac{\partial \mathrm{B}}{\partial \mathrm{r}} & =\frac{\partial \mathrm{F}}{\partial \mathrm{r}}=\frac{\partial \mathrm{G}}{\partial \mathrm{r}}=\frac{\partial \mathrm{S}}{\partial \mathrm{r}}=\left.0\right|_{r=r_{0}} \\
\mathrm{E} & =\left.\mathrm{E}_{0}\right|_{\mathrm{r}=\mathrm{r}_{0}} \\
\theta & =\left.1\right|_{\mathrm{r}=\mathrm{r}_{0}}
\end{aligned}
$$

The initial conditions for all state variables were set uniform, with values taken from measurements of the soil samples before incubation. Microbial biomass was converted from total microbial PLFA content as follows: $1 \mathrm{nmol}$ microbial PLFAs $=$ $3.2 \mu \mathrm{g}$ microbial biomass C (Willers et al., 2015).

\section{Aggregation Model}

An energy-based approach is applied to obtain aggregate size distribution from the modeled rhizosphere pattern. We adopt the assumption that the energy required for aggregate formation is proportional to the newly formed surface (Rittinger's law). Soil binding strength at each point in space is defined as the energy required to create a unit of new surface (v). It depends on the concentration of gluing agents and fungal biomass:

$$
\mathrm{v}=\left(1+\mathrm{v}_{1} \mathrm{G}+\mathrm{v}_{2} \mathrm{~F}\right) \times \frac{1+\theta_{\mathrm{a}}}{\theta+\theta_{\mathrm{a}}}
$$

The unit of soil binding strength is expressed relative to the minumum binding strength $(\mathrm{v}=1)$ which is given when no gluing agents or fungi are present and the soil is fully water saturated $(G=0, F=0, \theta=1)$. From the spatial pattern of soil binding strength we obtain the distribution of aggregate size classes by applying disrupting force $\mathrm{p}_{\mathrm{d}}$ (energy per unit volume). An aggregate of a certain radius is stable against disrupting force if the energy needed to form an aggregate surface $\left(\mathrm{vr}^{2}\right)$ is greater or equal to the energy applied to the aggregate volume $\left(r^{3} p_{d}\right)$. This results in a larger aggregate radius with larger binding strength and smaller disrupting force $\left(r=v / p_{d}\right)$. We assume that $\mathrm{p}_{\mathrm{d}}$ is distributed according to truncated normal probability $\left(\mathrm{p}_{\mathrm{d}}\right.$ $>0$ ) with a mean value $\mathrm{p}_{0}$ and a standard deviation $\sigma=0.5 \mathrm{p}_{0}$, where $\mathrm{p}_{0}$ is estimated from fitting procedure.

\section{Parameter Estimates}

The model parameters of the biochemical submodel were estimated by fitting the modeled total microbial biomass, fungal biomass, total OC content, and the relative distribution of aggregate size classes at the end of the incubation period to measured ones using the Nelder-Mead optimization method (Nelder and Mead, 1965). We calculated integrals $\mathrm{I}^{\mathrm{ijk}}$ of the 
model state variables B, F, and S over the sample volume:

$$
\mathrm{I}^{\mathrm{ijk}}=\int_{\mathrm{a}_{\mathrm{k}}}^{\mathrm{b}_{\mathrm{k}}} \mathrm{u}_{\mathrm{ij}} \mathrm{rdr}
$$

where $\mathrm{u}_{\mathrm{ij}}$ is the simulation result for variable $\mathrm{i} \in(\mathrm{B}, \mathrm{F}, \mathrm{S})$ and treatment $j$, whereas $k$ is either rhizosphere (RS in the equation) or bulk soil (BS in the equation) with $\mathrm{a}_{\mathrm{RS}}=\mathrm{r}_{0}, \mathrm{~b}_{\mathrm{RS}}=\mathrm{r}_{0}+6$, $\mathrm{a}_{\mathrm{BS}}$ $=\mathrm{r}_{0}+6, \mathrm{~b}_{\mathrm{BS}}=\mathrm{r}_{1}$.

In total, for the three variables, three exudate addition treatments and two sampling regions (rhizosphere and bulk soil), 18 data points were obtained for topsoil and 18 for the subsoil. Topsoil and subsoil parameters were fitted independently.

The objective function for minimization is a sum of logarithmic residuals squared of the abovementioned integrals:

$$
\sum_{\mathrm{i}, \mathrm{j}, \mathrm{k}}\left[\log \left(\mathrm{I}_{\mathrm{exp}}^{\mathrm{ijk}}\right)-\log \left(\mathrm{I}_{\text {model }}^{\mathrm{ijk}}\right)\right]^{2}
$$

The parameters for aggregation were estimated with a similar procedure according to Equations (22) and (23), where index i corresponds to aggregate size fraction instead of state variable, giving also 18 points of aggregate size distributions for each subsoil and topsoil. We modeled fractions $53-20$ and $<20 \mu \mathrm{m}$ as one aggregate size fraction, due to the small share of material in the aggregate size class $<20 \mu \mathrm{m}$.

\section{Statistical Analysis}

All statistical analyses were performed using SPSS Statistics 24 (IBM, Armonk, NY, USA). All variables were tested for normality using the Shapiro-Wilk test and for homogeneity of variance using Levene's test. Treatment means were tested for significant differences within the soil region (rhizosphere and bulk soil) and depth using analysis of variance (ANOVA) followed by Tukey's post-hoc test or the non-parametric Kruskal-Wallis test followed by the Wilcoxon test, depending on whether the assumption of normality and homogeneity of variance were met. The differences between soil regions were tested using paired $t$-test. We refer to a $p$-value $\leq 0.05$ as statistically significant. To estimate the exudate addition treatment strength in comparison to the water control samples, standardized effect sizes were calculated as biascorrected Hedges' g* values (Hedges and Olkin, 1985):

$$
\begin{aligned}
\mathrm{g} & =\frac{\mathrm{x}_{\mathrm{t}}-\mathrm{x}_{\mathrm{c}}}{\sqrt{\frac{\left(\mathrm{n}_{\mathrm{t}}-1\right) \bullet_{\mathrm{t}}^{2}+\left(\mathrm{n}_{\mathrm{c}}-1\right) \bullet_{\mathrm{c}}^{2}}{\mathrm{n}_{\mathrm{t}}+\mathrm{n}_{\mathrm{c}}-2}}} \\
\mathrm{~g}^{*} & =\mathrm{g} \bullet\left(1-\frac{3}{4\left(\mathrm{n}_{\mathrm{t}}+\mathrm{n}_{\mathrm{c}}\right)-9}\right)
\end{aligned}
$$

According to Cohen (1988), the effect sizes are classified as small $(<0.2)$, medium $(<0.5)$, and large $(>0.8)$.

\section{RESULTS}

\section{Basic Soil Properties}

The soil material before incubation varied considerably between topsoil and subsoil (Table 1). The OC content of the topsoil amounted to $33.3 \mathrm{mg} \mathrm{g}^{-1}$, whereas it was only $3.3 \mathrm{mg} \mathrm{g}^{-1}$ in the subsoil. The $\mathrm{C} / \mathrm{N}$ ratio decreased by almost $50 \%$ from 14 to 8 with soil depth. In contrast, soil texture was similar at the two soil depths. Microbial residues as determined by the AS content strongly increased with depth from 26 to $46 \mu \mathrm{g}$ AS C $\mathrm{g}^{-1}$ SOC when standardized to SOC content. The aggregate size class distribution varied between soil depths. In the topsoil, the relative abundance of the water-stable aggregate size fractions decreased with aggregate size. Macroaggregates $>250 \mu \mathrm{m}$ thereby comprised the largest fraction, which accounted for $\sim 50 \%$ of the topsoil mass. In the subsoil, macroaggregates made up only $25 \%$ of the soil mass, whereas the large microaggregate fraction $(250-53 \mu \mathrm{m})$ clearly dominated with a contribution of more than $50 \%$. The OC and $\mathrm{N}$ contents of the aggregates decreased with size for the aggregate fractions from $>250$ to $53-20 \mu \mathrm{m}$ and then increased again in the aggregate fraction $<20 \mu \mathrm{m}$. Although this pattern was observed in soils sampled from either depth, macroaggregates had by far the highest OC concentrations of the topsoil aggregates $\left(42 \mathrm{mg} \mathrm{g}^{-1}\right)$, whereas the fraction $<20 \mu \mathrm{m}$ was the one with the highest OC concentrations in the subsoil $\left(6.6 \mathrm{mg} \mathrm{g}^{-1}\right)$. The $\mathrm{C} / \mathrm{N}$ ratio was generally lower in the subsoil aggregate fractions than in the topsoil aggregate fractions and was particularly low in DOM (6 and 5 for topsoil and subsoil, respectively) (Table 1).

Comparing the soil before incubation with the water control samples, it can be seen that incubation slightly decreased OC contents in soils from both depths (Tables 1, 3). In addition, the total PLFA content as a measure of microbial biomass decreased during the incubation from $134 \mathrm{nmol} \mathrm{g}{ }^{-1}$ before incubation to $98 \mathrm{nmol} \mathrm{g}^{-1}$ for the water control in the topsoil and from 4.4 to $3.7 \mathrm{nmol} \mathrm{g}^{-1}$ in the subsoil (Table 1; Figure 3A).

\section{Organic Carbon and Total Nitrogen Contents}

Within the topsoil rhizosphere, the addition of exudate solutions did not induce statistically significant effects regarding $\mathrm{OC}$ and $\mathrm{N}$ contents compared with the water control $\left(32.98 \mathrm{mg} \mathrm{OC} \mathrm{g}^{-1}\right.$ and $3.21 \mathrm{mg} \mathrm{N} \mathrm{g}^{-1}$ ). However, the OC and $\mathrm{N}$ contents both slightly decreased after moderate exudate additions $\left(32.37 \mathrm{mg} \mathrm{OC} \mathrm{\textrm {g } ^ { - 1 }}\right.$ and $3.13 \mathrm{mg} \mathrm{N} \mathrm{g}^{-1}$ ), which was reflected by a strong negative effect size $(-1.6)$ and resulted in a significant difference from high exudate additions $\left(33.22 \mathrm{mg} \mathrm{OC} \mathrm{g}^{-1}\right.$ and $3.52 \mathrm{mg} \mathrm{N} \mathrm{g}^{-1}$, $p=0.034$ ). In the subsoil rhizosphere, high exudate additions led to significantly increased $\mathrm{OC}$ and $\mathrm{N}$ contents, with a high positive effect size (+4.6) for subsoil OC contents. Moderate exudate additions had a strong negative effect size $(-2.7)$ for subsoil OC contents (Table 3; Figure 2). The $\mathrm{C} / \mathrm{N}$ ratio significantly widened from 7.9 in the water control to 8.3 with high treatment (Table 3).

Bulk soil showed no treatment response over soils sampled from either depth. It did, however, partly differ from the rhizosphere: In the topsoil water control, OC and $\mathrm{N}$ contents were significantly higher in the rhizosphere than in the bulk soil. In both topsoil and subsoil, high exudate additions led to increased $\mathrm{OC}$ and $\mathrm{N}$ concentrations in the rhizosphere compared with the bulk soil, being significant in the subsoil. Furthermore, in the subsoil samples treated with moderate exudate additions, 
TABLE 3 | Organic carbon $(\mathrm{OC})$ and nitrogen $(\mathrm{N})$ contents and the $\mathrm{C} / \mathrm{N}$ ratio.

\begin{tabular}{|c|c|c|c|c|c|c|c|}
\hline & & \multicolumn{3}{|c|}{ Topsoil } & \multicolumn{3}{|c|}{ Subsoil } \\
\hline & & Water control & Moderate & High & Water control & Moderate & High \\
\hline \multirow[t]{2}{*}{ OC content ( $\left.\mathrm{mg} \mathrm{g}^{-1}\right)$} & Rhizosphere & $\mathrm{ab}_{32.98(0.40)}$ & $\mathbf{a}_{32.37}(0.23)$ & $\mathbf{b}_{33.22(0.51)}$ & $\mathbf{a}_{3.21(0.02)}$ & $a_{3.13}(0.03)$ & $\mathrm{b}_{3.52(0.08)}$ \\
\hline & Bulk soil & $32.01(0.43)$ & $32.77(0.61)$ & 32.96 (1.03) & $3.21(0.14)$ & $3.14(0.06)$ & $3.20(0.05)$ \\
\hline \multirow[t]{2}{*}{$\mathrm{N}$ content $\left(\mathrm{mg} \mathrm{g}^{-1}\right)$} & Rhizosphere & $\mathrm{ab}_{2.29}(0.01)$ & $\mathbf{a}_{2.25}(0.03)$ & $\mathbf{b}_{2.33}(0.04)$ & $\mathbf{a}_{0.41(0.00)}$ & $\mathbf{a}_{0.40}(0.00)$ & ${ }^{b} 0.42(0.01)$ \\
\hline & Bulk soil & $2.23(0.02)$ & $2.28(0.04)$ & $2.28(0.11)$ & $0.40(0.01)$ & $0.39(0.01)$ & $0.39(0.00)$ \\
\hline \multirow[t]{2}{*}{ C:N ratio } & Rhizosphere & $14.42(0.18)$ & $14.41(0.15)$ & $14.25(0.11)$ & $\mathbf{a}_{7.92}(0.04)$ & $a_{7.81}(0.07)$ & $\mathbf{b}_{8.34}(0.12)$ \\
\hline & Bulk soil & $14.33(0.12)$ & $14.37(0.16)$ & $14.44(0.47)$ & $8.05(0.30)$ & 7.97 (0.13) & $8.17(0.09)$ \\
\hline
\end{tabular}

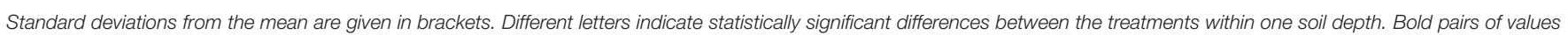
indicate statistically significant differences between the rhizosphere and bulk soil within one soil depth and treatment $(p<0.05)$.

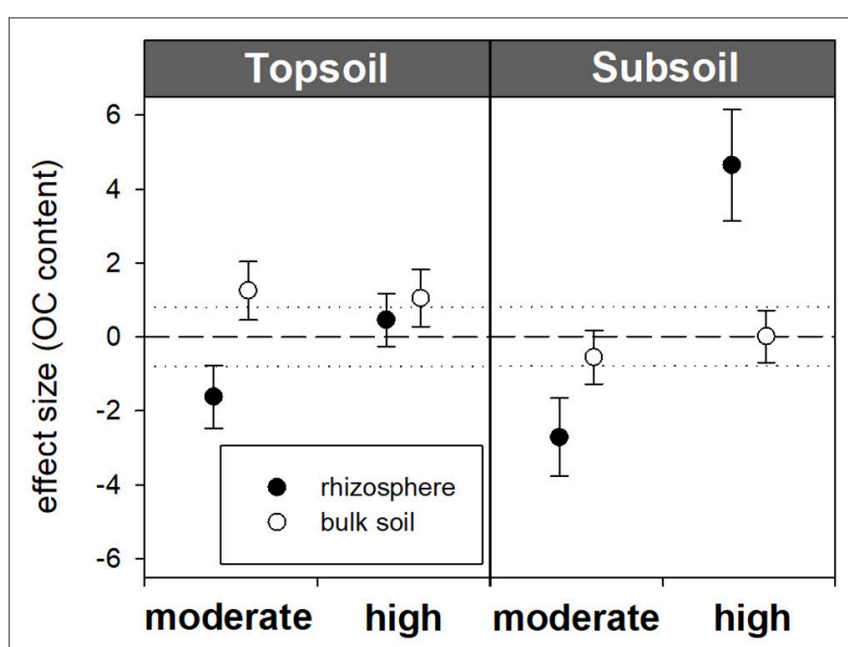

FIGURE 2 | Standardized effect sizes for total OC contents. Hedges' $\mathrm{g}^{\star}$ of the exudate addition treatments compared to the water control. Bars indicate the standard error of the effect size estimate. Dotted lines mark thresholds of -0.8 and 0.8 below or above which, respectively, effect sizes are considered as high.

the $\mathrm{C} / \mathrm{N}$ ratio was lower in the rhizosphere than in the bulk soil (Table 3).

\section{Microbial Biomarkers}

The AS contents of the samples did not respond to the exudate additions, neither when standardized to soil DW, nor to soil OC content. The same holds true for the $\mathrm{F}: \mathrm{B}_{\mathrm{AS}}$ ratio (Table S1).

Contrary to the AS data, PLFA analysis revealed a pronounced effect of artificial exudate additions on microbial community composition as well as microbial biomass (indicated by the total microbial PLFA content). The total microbial PLFA content in the topsoil rhizosphere tended to increase in the high exudate addition treatment $\left(124.6 \mathrm{nmol} \mathrm{g}^{-1}\right)$ compared with the water control $\left(98.1 \mathrm{nmol} \mathrm{g}^{-1}, p<0.1\right)$. This was accompanied by a high effect size of +1.8 . In the subsoil rhizosphere, a high positive effect size was observed for moderate exudate supply. Although this effect was not statistically significant, the total microbial PLFA content increased from $3.7 \mathrm{nmol} \mathrm{g}^{-1}$ in the water control to $5.1 \mathrm{nmol} \mathrm{g}^{-1}$ in the moderate treatment. The high exudate addition treatment strongly increased total microbial PLFA content in the subsoil rhizosphere by more than $300 \%$ to $11.2 \mathrm{nmol} \mathrm{g}^{-1}$ (Figures 3A, 4A).

High exudate additions significantly increased the total microbial PLFA content in the rhizosphere as compared with the bulk soil in soils sampled from either depth. The same holds true for the moderately treated samples in the subsoil (Figure 3A).

For the topsoil as well as the subsoil, high exudate supply led to a significant increase in F:B PLFA ratio compared with the water control and the moderate treatment. It increased from 0.4 to 0.7 (effect size +2.0 ) in the topsoil and from 0.3 to 2.5 (effect size +4.7 ) in the subsoil in the water control and high exudate addition treatment samples, respectively. The latter, extreme effect was also visible in the bulk soil, where it increased F:B BLFA from 0.3 to 0.7 and produced a high effect size of +4.96 (Figures 3B, 4B).

Compared with the respective bulk soil, F:BPLFA was significantly higher in the rhizosphere of the subsoil samples receiving moderate treatment and in the rhizosphere of both topsoil and subsoil samples receiving the high treatment (Figure 3B).

\section{Aggregate Size Classes}

The relative distribution of aggregate size classes in the topsoil rhizosphere did not show statistically significant responses to the two exudate addition treatments. However, high exudate supply tended to induce the formation of macroaggregates as their relative abundance increased from $51 \%$ in the water control to $57 \%$ in the high exudate addition treatment $(p=0.07$, effect size +3.4). In contrast, moderate exudate supply negatively affected macroaggregation (effect size -0.97) (Figures 5, 6). This caused significant differences between the moderate and the high exudate addition treatments for all aggregate fractions $>20 \mu \mathrm{m}$ (Figure 5). In the subsoil rhizosphere, the distribution of aggregate size classes was strongly affected by high exudate addition treatment: the macroaggregate abundance increased by $89 \%$ compared with the water control (effect size +6.6 ). This effect was accompanied by a decrease in all microaggregate fractions, but mostly the aggregates $250-53 \mu \mathrm{m}$ in size (Figure 5).

In the bulk topsoil, the aggregate size distribution differed significantly from that of both the soil before incubation and the rhizosphere (Table 1; Figure 5). In comparison to the rhizosphere, the relative abundance of macroaggregates in the 

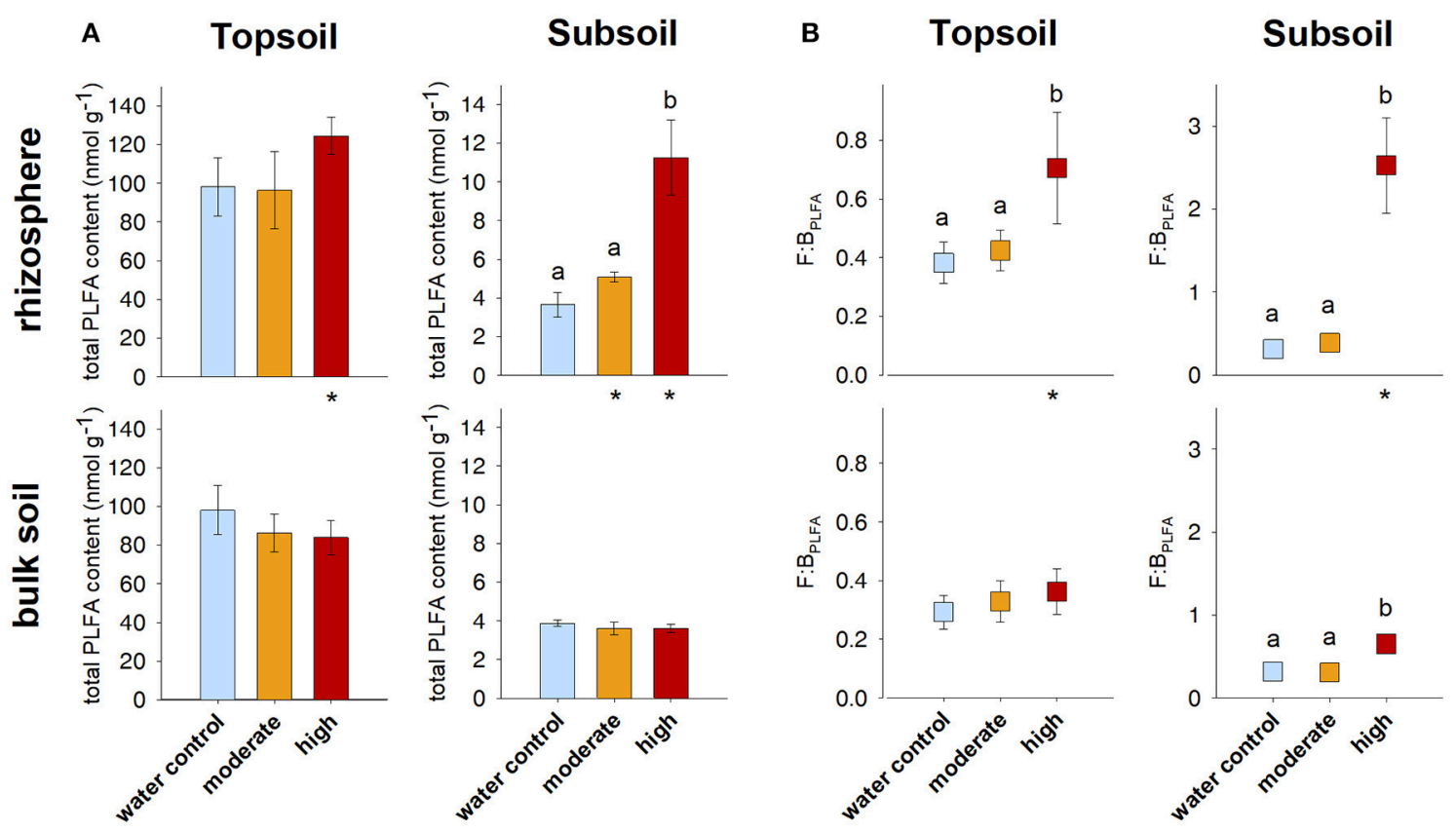

FIGURE 3 | (A) Total microbial PLFA content and (B) fungal-to-bacterial ratio based on PLFA analysis (F:BPLFA). Bars represent standard deviation from the mean (SD). Different letters indicate statistically significant differences between the treatments within one soil region and depth ( $p<0.05)$, asterisks indicate statistically significant differences between the soil regions rhizosphere and bulk soil within one soil depth and treatment.

bulk soil was significantly enhanced by $\sim 25 \%$ over all treatments. This was accompanied by a decrease in large microaggregates $(250-53 \mu \mathrm{m})$ in all treatments as well as a decrease in smaller microaggregates in the moderately treated samples.

In the subsoil, the above mentioned strong effect of the high exudate additions in the rhizosphere also led to significant differences with respect to the bulk soil in all aggregate size classes $>20 \mu \mathrm{m}$ for this treatment. Furthermore, macroaggregates increased and large microaggregates (250$53 \mu \mathrm{m}$ ) decreased in the bulk soil of the water control compared with the respective rhizosphere (Figure 5). In addition to these differences between the bulk soil and the rhizosphere, there occurred a significant treatment effect within the bulk topsoil: The samples treated with moderate exudate additions showed higher macroaggregation and correspondingly lower relative proportion of free microaggregation than the water control and the highexudate addition treatment (Figure 5).

The relative contributions of the individual water-stable aggregate size classes to total OC contents were mainly governed by the mass distribution of the aggregate size classes themselves (Figure S2). Moderate exudate additions significantly increased the share of water-stable aggregate size classes on total OC in the subsoil rhizosphere (Figure S2, Table S2) as well as the total amount of DOC (Table S3).

\section{Modeled Soil Aggregation}

The modeled average microbial biomass, fungal biomass, OC concentration, and distribution of water-stable aggregate size classes fit well with the experimental data, as shown in 1:1 plots (Figure S3). The spatially explicit model demonstrates that soluble root exudates influence soil up to a distance of $6 \mathrm{~mm}$ around the artificial root, which affirms the choice of rhizosphere boundary in the incubation experiment (Figure 7).

The model parameter estimates reveal SOM to be more stable against biotic and abiotic breakdown in the subsoil (lower coefficient $\mathrm{k}_{\mathrm{S}}$ and zero $\mathrm{k}_{\mathrm{S} 0}$ ) and to have a lower capacity for microbial growth (lower $\mathrm{m}_{0}$ and $\mathrm{m}_{1}$ ), and overall slower biochemical processes $\left(\mathrm{k}_{1}-\mathrm{k}_{4}\right.$; Table 2$)$. This may reflect either differences in chemical composition or spatial restrictions for enzymatic breakdown and substrate consumption at lower SOC concentrations in the subsoil. In contrast, the production of gluing agents by lysis $\left(k_{r}\right)$ is greater in the subsoil than in the topsoil. The lower $\theta_{\mathrm{a}}$ in the topsoil compared with the subsoil (Table 2) indicates that moisture has a more negative effect on the binding strength in the topsoil.

Total microbial as well as fungal biomass showed similar patterns with distance from the root. After moderate and high exudate additions, biomass was predicted to strongly increase in the rhizosphere at both soil depths. In the topsoil, this effect reached out only $1-2 \mathrm{~mm}$, whereas in the subsoil, it influenced a larger area of soil (3-6 mm distance from the root; Figures 7A,B). The model results of organic gluing agent concentrations also showed an increase relative to exudate addition rate in soils sampled from either depth. Again, a smaller soil volume was affected in the topsoil than in the subsoil. The amount of gluing agents in the water control was slightly decreased in close proximity to the root (Figure 7C). The modeled total 

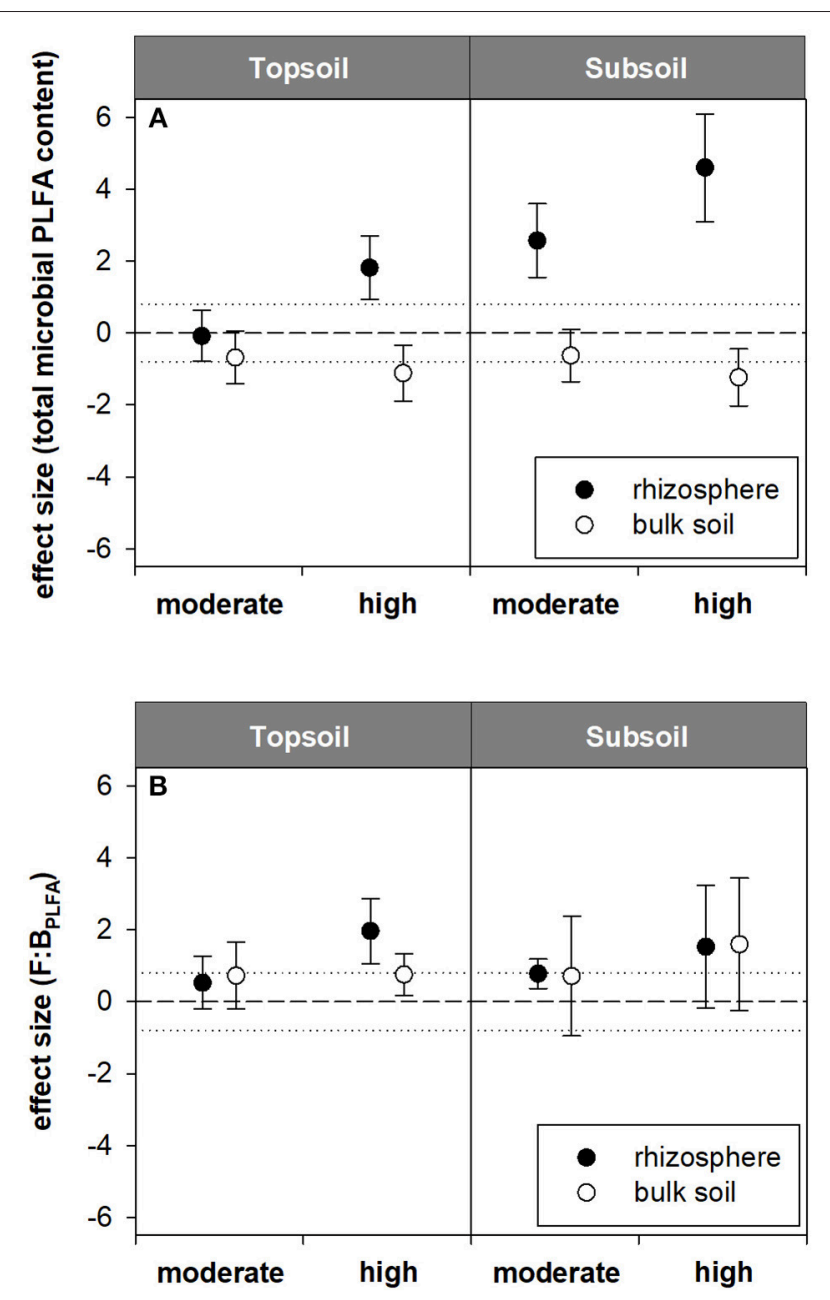

FIGURE 4 | Standardized effect sizes for (A) total microbial PLFA content and (B) F:BPLFA ratio. Hedges' $g^{\star}$ of the exudate addition treatments compared to the water control. Bars indicate the standard error of the effect size estimate. Dotted lines mark thresholds of -0.8 and 0.8 below or above which, respectively, effect sizes are considered as high.

OC content increased with exudate additions in the subsoil. In the topsoil, however, a divergent effect was predicted by the model: Moderate exudate additions decreased total OC content, whereas the high exudate addition treatment was predicted to induce a strong but spatially limited increase in total OC content (Figure 7D). Modeled soil moisture formed a negative gradient with distance from the root (Figure 7E). This, together with the spatial patterns of the abundance of fungi and gluing agents, resulted in the soil binding strength responsible for the formation of water-stable aggregates (Figure 7F). The soil binding strength profile for the topsoil water control reveals that the binding strength increases with distance from the artificial root, leading to higher aggregation in the bulk soil. For the exudate addition treatments in turn, binding strength was the highest in close proximity to the root and decreased toward the bulk soil. Topsoil binding strength profiles were overall similar to those of the subsoil. However, the profiles of the exudate amended soils showed minima at $1-2 \mathrm{~mm}$ distance from the root (Figure 7F).

\section{DISCUSSION}

\section{Accelerated Macroaggregation With the Addition of Labile C}

Our study clearly demonstrates that artificially high doses of root exudates induce strong positive effects on soil structure, which are accompanied by a change in microbial community composition. High exudate treatment strongly increased macroaggregation compared with the water control and the moderate treatment in the subsoil rhizosphere. In the topsoil rhizosphere, a similar trend was observed (Figures 5, 6). Furthermore, high exudate treatment induced strong fungal growth, as indicated by the significant increase in F:BPLA in samples from both soil depths. In the C-poor subsoil, this effect was more pronounced, which even extended to the bulk soil region (Figures 3B, 4B) and was also visually evident as fungal mycelium in the soil around the artificial roots of some samples at harvest. This observation is in contrast with the modeling data where no influence of root exudates beyond a distance of $6 \mathrm{~mm}$ from the root surface was predicted. However, fungal biomass in the subsoil was affected over a larger distance from the root than that in the topsoil (Figure 7B). Fungi have been found to utilize rhizodeposits more intensely than bacteria (Butler et al., 2003). Consequently, high addition rates of root exudates favor a shift in the microbial community composition toward higher relative abundance of fungi (Griffiths et al., 1998). It is well-documented that fungi are important agents in the formation of macroaggregates (Amézketa, 1999; Helfrich et al., 2008; Lehmann et al., 2017). We assume that the significantly increased fungal biomass due to high exudate additions led to enhanced subsoil macroaggregation in our study. The concomitant significant decrease in free aggregates 250$53 \mu \mathrm{m}$ in size points toward the formation of macroaggregates particularly out of big microaggregates (Figure 5) and thus supports the aggregate hierarchy model, a conceptual framework that hypothesizes that microaggregates are glued together by temporary binding agents, such as roots and hyphae (Tisdall and Oades, 1982; Oades and Waters, 1991). The absence of any trend with respect to the amount of AS (Table S1) is in strong contrast to the distinct response of PLFA contents to the artificial exudate additions. Amino sugars are promising indicators when it comes to integrating long-term changes in microbial community structure, but may not be suitable for analyzing the effects of a relatively short incubation experiment, such as ours (Glaser et al., 2004).

\section{Mechanisms of Macroaggregation in Topsoil and Subsoil}

It is often observed that most of the SOC in subsoils is stored in clay- and silt-sized mineral fractions (Angst et al., 2018) via the formation of organomineral associations. Therefore, the occlusion of SOM within aggregates has long been a rather disregarded mechanism for $\mathrm{C}$ storage in deep soil layers (Lorenz 


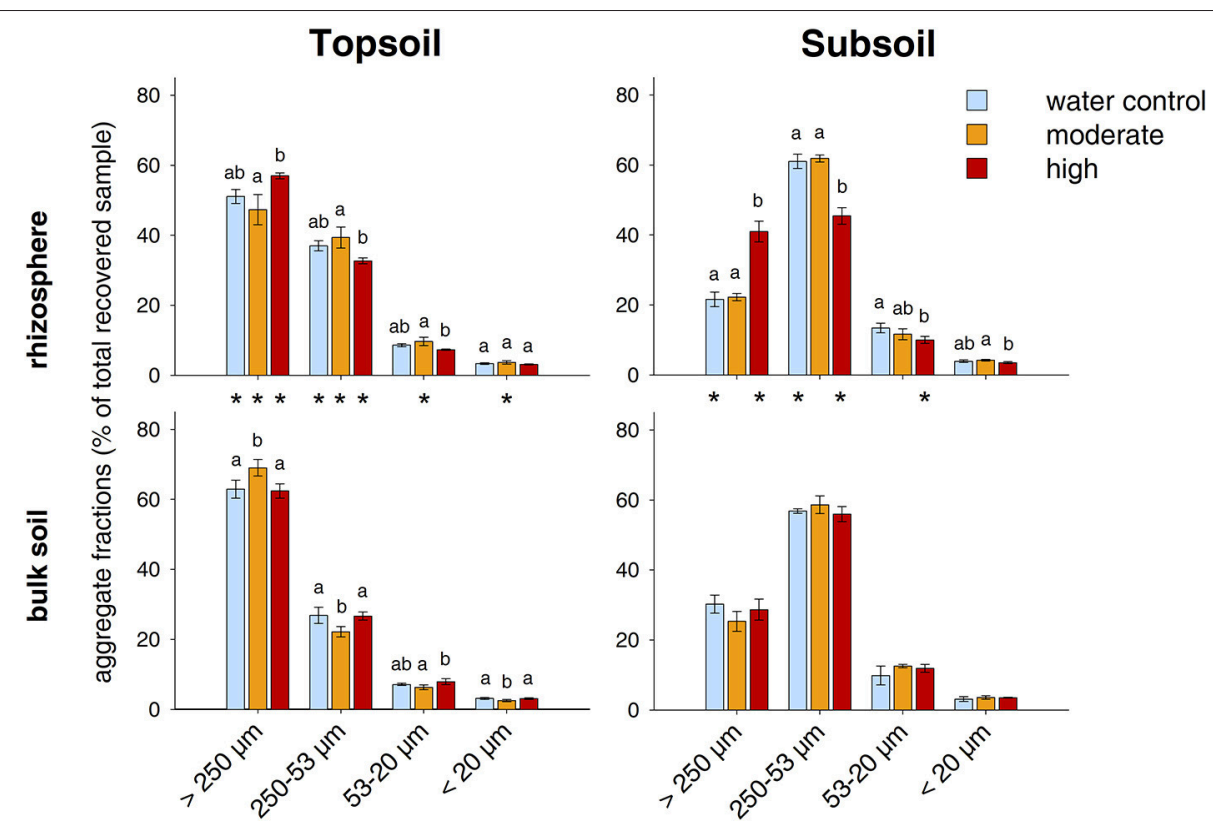

FIGURE 5 | Distribution of water-stable aggregate size classes. Bars represent standard deviation from the mean (SD). Different letters indicate statistically significant differences between the treatments within one soil region and depth $(p<0.05)$, asterisks indicate statistically significant differences between the soil regions rhizosphere and bulk soil within one soil depth and treatment.

and Lal, 2005; von Lützow et al., 2006). The soil studied here was well aggregated in samples from both soil depths: although the soil had a silty loam texture with more than 90 $\%$ primary particles $<53 \mu \mathrm{m}$ (Table 1 ), the particles $<53 \mu \mathrm{m}$ obtained by aggregate fractionation amounted to $<20 \%$ of the soil mass in both depths and contained approximately only 10 and $30 \%$ of the total SOC in topsoil and subsoil, respectively (Figure 5; Figure S2). Aggregation is known to greatly increase the persistence of SOM via occlusion, thus providing physical protection from decomposition (Dungait et al., 2012), and it has been shown that this is also the case in C-poor subsoils (Rasmussen et al., 2005; Schrumpf et al., 2013). Our findings show that the effects of high exudate $\mathrm{C}$ addition rates were much more pronounced in the subsoil than in the topsoil presumably because the C-rich topsoils are already well aggregated due to the high amount of SOM and organic gluing agents. The modeled coefficients of the effect of gluing agents and fungi on binding strength $\left(\mathrm{v}_{1}, \mathrm{v}_{2}\right)$ furthermore revealed that their influence on aggregation is stronger in subsoils than in topsoils. In the topsoil, water-stable macroaggregates made up more than $50 \%$ of the soil mass before incubation and also stored most of the OC. In contrast, the subsoil was characterized by substantially less macroaggregation because it comprised $60 \%$ large microaggregates $(250-53 \mu \mathrm{m})$. In soils sampled from either depth, macroaggregates showed higher OC contents than the microaggregates they were composed of (Table 1). This reveals that for the formation of macroaggregates, OC is needed, presumably in the form of $\mathrm{OM}$ as binding agents (Tisdall and Oades, 1982). It has been speculated that the mechanisms of aggregation in topsoils and subsoils are different and that in subsoils physical processes may be more important than biological processes (Lorenz and Lal, 2005; von Lützow et al., 2006; Rumpel and Kögel-Knabner, 2011). Based on our results, we assume that biologically-induced macroaggregation in subsoils may be limited by the scarce and heterogeneous input of $\mathrm{OM}$. We prove that the addition of OM at high rates may boost biotic macroaggregation by the growth of fungi and strongly alter subsoil structure within relatively short time scales. The high positive effect sizes for total PLFA content as well as F:B PLFA after the moderate exudation treatment indicate that similar processes might be triggered by moderate rates of root exudates in the long term (Figure 4). Thus, the deficiency of OC appears to be causative for the limitation of biotic macroaggregation in the subsoil and can be alleviated by the addition of OM, such as soluble root exudates. The high experimental exudate additions in our study exceed naturally occurring $\mathrm{C}$ input by root exudates, yet rhizodeposition may increase under rising $\mathrm{CO}_{2}$ concentrations (Phillips et al., 2006; Keidel et al., 2018). Our study indicates that deep soil layers containing less (macro)aggregates may harbor a higher potential for further aggregation and thereby C stabilization than topsoils if supplied with additional OM.

Bulk topsoil exhibited a significantly higher relative abundance of macroaggregates than the rhizosphere (Figure 5). Because neither $\mathrm{OC}$ content nor $\mathrm{F}: \mathrm{B}_{\mathrm{AS}}$ ratio in the bulk topsoil was elevated in comparison to the rhizosphere, this enhanced macroaggregation did not appear to be induced by the addition of SOM or the growth of fungi. Thus, we presume that macroaggregation in the bulk topsoil occurred in response to abiotic causes. The aggregation model confirmed this hypothesis, because the differences in aggregation between the rhizosphere 

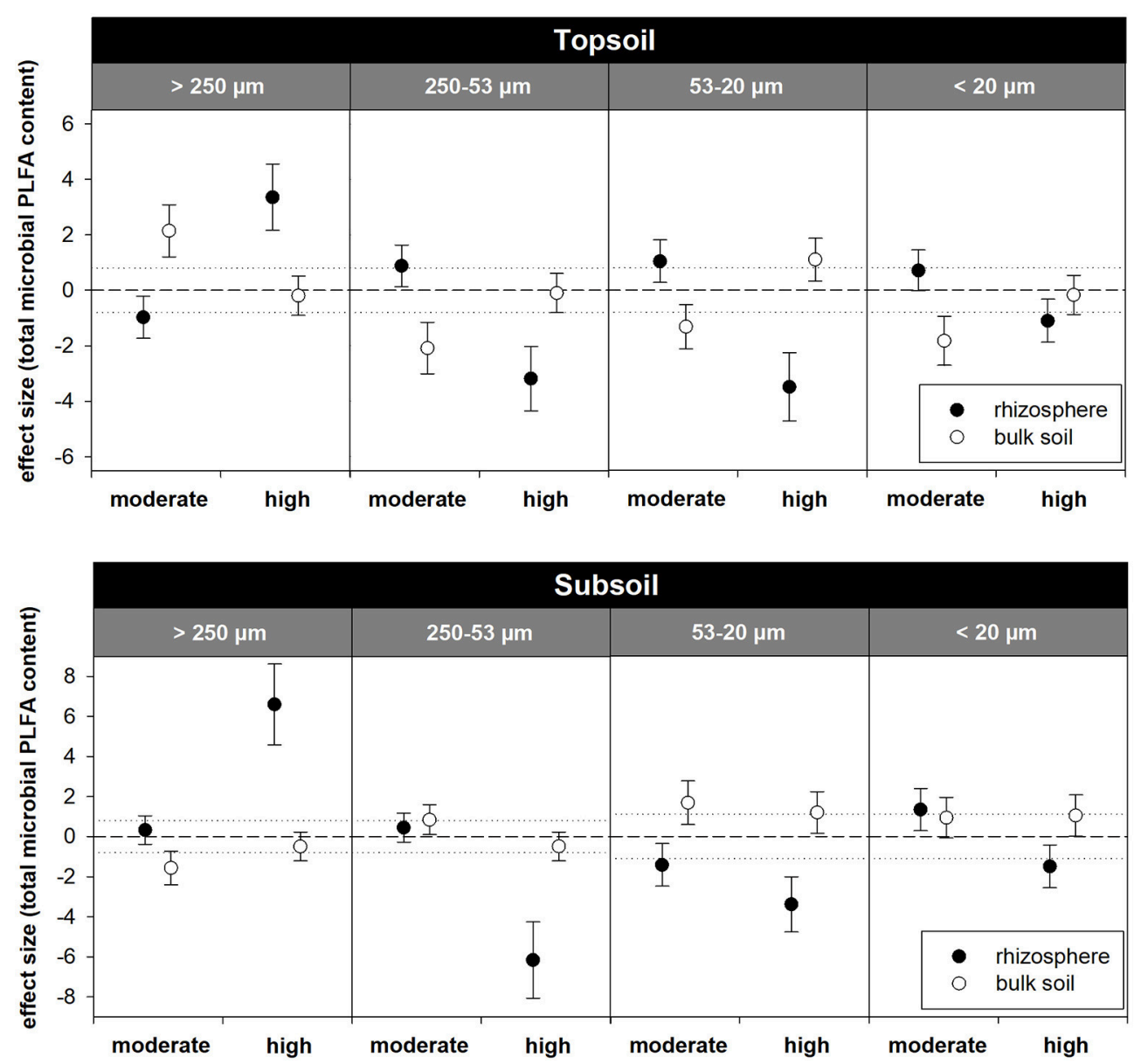

FIGURE 6 | Standardized effect sizes for the distribution of water-stable aggregate size classes. Hedges' $\mathrm{g}^{\star}$ of the exudate addition treatments compared to the water control. Bars indicate the standard error of the effect size estimate. Dotted lines mark thresholds of -0.8 and 0.8 below or above which, respectively, effect sizes are considered as high.

and bulk soil samples can be described well via a moisture factor. Soil moisture is assumed to affect aggregation by slaking and by its influence on SOM decomposition rates and thereby the microbial decay of gluing agents. Although we did not measure soil moisture within the individual sampling regions, we assume drier conditions in the bulk soil compared with the rhizosphere, which presumably favored the development of stable aggregates (Caron et al., 1992). The hypothesis of higher amounts of water within the rhizosphere is in accordance with the findings of Carminati et al. (2010).

\section{Importance of the Choice of Exudate Addition Rates}

Moderate exudate additions induced a trend of decreased OC content in samples from both soil depths (Table 3; Figure 2), significantly increased DOM abundance in the subsoil rhizosphere (Tables S2, S3; Figure S2), and negatively affected macroaggregation in the topsoil rhizosphere (Figure 5). Although we did not measure soil respiration to determine the possible priming effects in our study, these findings may indicate the occurrence of such an effect and hence the decomposition of native SOM in response to the addition of moderate exudate concentration. Root exudation by tree seedlings (with rates similar to that of our moderate treatment) was found to strongly enhance SOM decomposition and $\mathrm{N}$ mineralization (Bengtson et al., 2012). It is hypothesized that the relatively low amounts of labile $\mathrm{C}$ stimulate the synthesis of enzymes that decompose SOM (Bengtson et al., 2012), possibly to mine for nutrients (Dijkstra et al., 2013). This corroborates the findings of a study applying artificial root exudates over a range of concentrations, which found that the activity of enzymes that degrade fast-cycling $\mathrm{N}$ compounds was generally increased by artificial root exudates within the upper $10 \mathrm{~cm}$ of the soil (Meier et al., 2017). Surprisingly, in unfertilized soils, the most pronounced effect was triggered by the lowest exudate addition rate, which resembles our moderate treatment. Tian et al. (2016) found SOM within macroaggregates to be less protected against decomposition induced by glucose addition than that associated with microaggregates. Thus, OM acting as a gluing agent of macroaggregates appears to be prone 

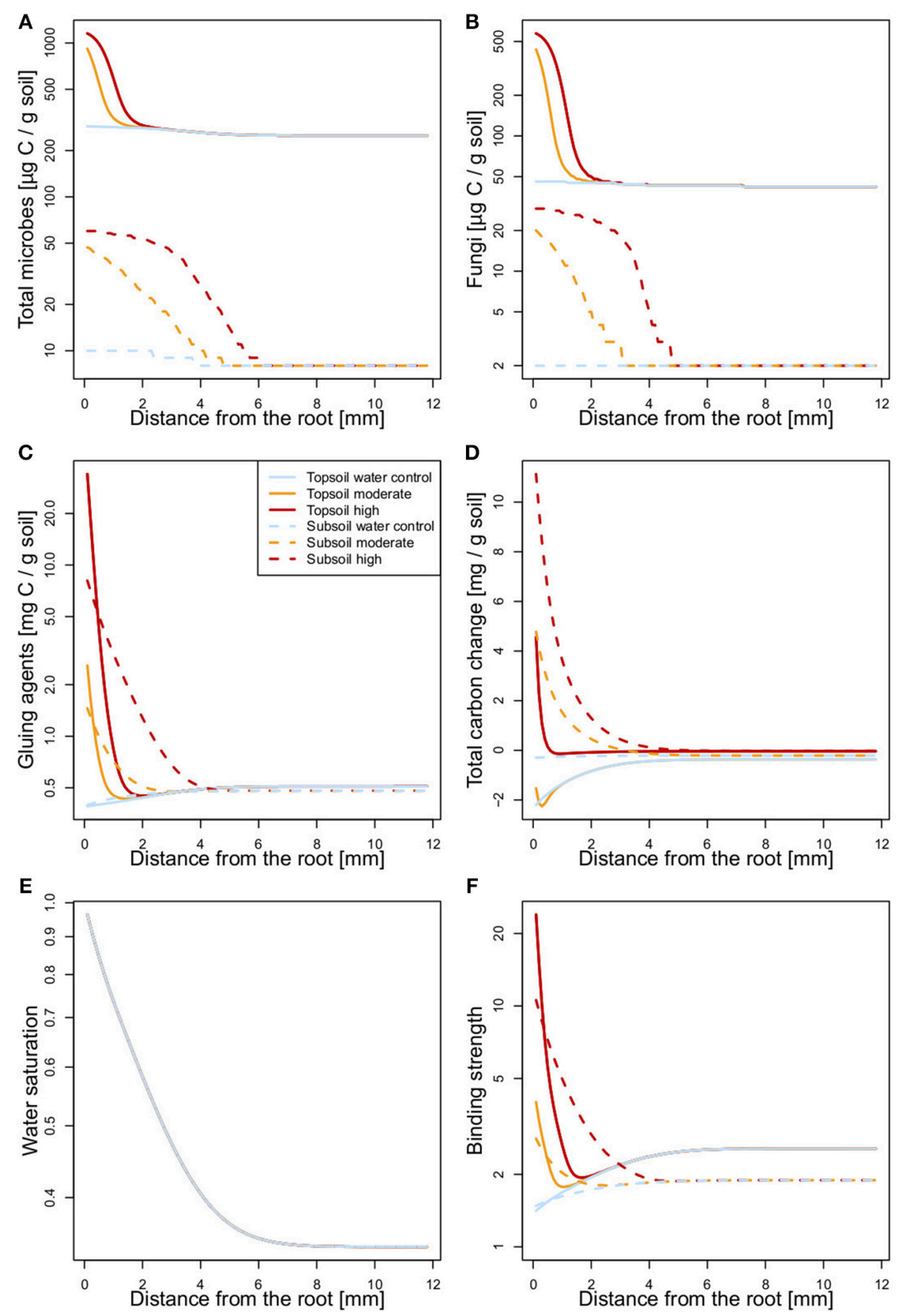

FIGURE 7 | State variables [(A) total microbial biomass, (B) fungal biomass, (C) concentration of gluing agents, (D) change in total OC, (E) water saturation], and (F) binding strength as functions of distance from the artificial root at the end of incubation. For total carbon change in case of the high exudate addition treatment the scale is multiplied by a factor of 0.1 .

to enhanced degradation after the moderate addition of root exudates, explaining the tendency toward disaggregation and breakup into smaller microaggregates in the topsoil (Figure 5). The model results confirm the observed decline in total OC due to moderate exudate addition treatment in the topsoil rhizosphere. In the subsoil rhizosphere, however, the model predicts an increase in total OC after moderate exudate additions. This indicates a higher potential for the accumulation of SOC due to the addition of root exudates in deeper soil layers than in the topsoil.

In contrast, as discussed above, the high exudate addition treatment strongly enhanced macroaggregation in the subsoil 
rhizosphere (Figure 5) and tended to do so in the topsoil (Figure 6). Furthermore, it strongly increased the $\mathrm{OC}$ and $\mathrm{N}$ concentrations of the rhizosphere in the subsoil (Table 3), indicating that the addition of such high amounts of labile $\mathrm{C}$ saturates the system. When exposed to very high $\mathrm{C}$ addition rates, soil microbes might preferentially utilize this abundant and easily available substrate (negative priming effect) instead of undertaking the above mentioned metabolic effort to decompose native SOM (Blagodatskaya and Kuzyakov, 2008; Bengtson et al., 2012; Wang et al., 2015). The high exudate addition treatment did not lead to increased amounts of DOM (Tables S2, S3; Figure S2), which proves that even these high concentrations were either sorbed to soil minerals or taken up by microbes to a large extent instead of remaining in a free state.

Microbial biomass (total microbial PLFA content) did not increase in response to the moderate treatment in the topsoil (Figure 3A). This confirms the observations of Drake et al. (2013) for exudates at similar concentrations. After high exudate additions, total PLFA content increased in soils sampled from either depth (Figures 3A, 4A). Priming effects after high additions of labile $\mathrm{C}$ are often accompanied by increases in microbial biomass (Huo et al., 2017), whereas trace amounts of substrates presumably only activate microorganisms (shift from dormant to active), thereby accelerating their metabolism but not inducing microbial growth, a mechanism referred to as the "triggering effect" (De Nobili et al., 2001; Mondini et al., 2006).

Our model scheme includes measured microbial pools as well as mechanisms necessary to describe change in substrate preference, which are both required to model priming effects (Georgiou et al., 2015). The predicted decline in topsoil OC content in response to moderate exudate additions indicates a positive priming or triggering effect. In contrast, SOC accumulation at high exudate additions may be the result of a negative priming effect, although experiments including isotopic labeling would be needed for proof.

Thus, both the experimental and modeled data suggest that different addition rates of root exudates induce opposing effects. This is in line with a meta-analysis by Blagodatskaya and Kuzyakov (2008), who found the relationship between substrate addition rate and priming to be nonlinear: The authors reported that low concentrations of labile $\mathrm{C}$ additions induced a linear increase in primed $\mathrm{CO}_{2}-\mathrm{C}$ efflux in agriculturally managed topsoils, whereas it decreased exponentially and eventually even became negative for high $\mathrm{C}$ addition rates. Hence, the choice of application rates in artificial root experiments is crucial regarding their interpretation and explanatory power. In previous artificial root exudate studies, addition rates were often not clearly attributable to natural root exudation rates or concentrations and possibly were chosen deliberately higher to certainly trigger measurable effects (Traoré et al., 2000; Keiluweit et al., 2015; Steinauer et al., 2016). We recommend for future studies to apply a range of exudate addition rates, including those representing natural soluble root exudation. That way, valuable and applicable knowledge on the effects of soluble root exudates on $\mathrm{C}$ dynamics can be gathered.

\section{CONCLUSION}

This study provides evidence that biotic aggregation in subsoils is promoted by increased provision of easily available $\mathrm{OM}$ in the rhizosphere. Our experimental data show that sufficient amendment with soluble root exudates induces biotic macroaggregation and $\mathrm{C}$ storage in subsoil horizons. This reveals a high potential for $\mathrm{C}$ sequestration via the physical protection of SOM in subsoils.

Furthermore, our study demonstrates that the impact of soluble root exudates on SOC storage and structural development differs substantially between the topsoil and subsoil. These effects tend to be divergent for different concentrations of exudates potentially due to the occurrence of positive and negative priming effects.

The proposed model of biochemical and biophysical processes involved in rhizosphere aggregation predicts the existence of different gradients with distance from the root and suggests future developments for the experimental design with spatial explicit measurements of moisture, bulk density, and aeration to simulate differences in conditions with depth.

For future studies, we recommend to test our results in different soil types by applying a range of exudate addition rates, including those representing natural soluble root exudation.

\section{AUTHOR CONTRIBUTIONS}

VB, IK-K, and CM designed the experiment. VB conducted the laboratory analyses, evaluated the experimental data, and wrote the manuscript. CM supervised the analyses. NV and AV performed mathematical modeling and drafted the paragraphs on modeling for the manuscript. IM provided data concerning the natural rates of root exudation. VB, NV, AV, IM, IK-K, and $\mathrm{CM}$ discussed the results, commented on the manuscript, and revised it for publication.

\section{FUNDING}

This work was financially supported by the Deutsche Forschungsgemeinschaft (German Research Foundation, DFG) and was conducted within the project Rhizosphere as driver of subsoil organic matter distribution and composition (MU 3021/4-2) in the frame of the DFG research unit FOR1806 The forgotten part of carbon cycling: Soil organic matter storage and turnover in subsoils (SUBSOM). Soil aggregate modeling was funded by the Russian Foundation for Basic Research (grant no. 16-04-01624, Dynamic modeling of formation mechanisms for soil profile aggregate structure).

\section{ACKNOWLEDGMENTS}

The authors would like to thank Dr. Stefanie Schulz and Gudrun Hufnagel for performing DOC and dNt measurements; Karolin Müller, Sebastian Preußer, and Sabine Rudolph for providing assistance with PLFA extraction; Stefanie Mayer for her help in texture analysis; and Timo Tückmantel for sharing 
information regarding natural exudation rates in European beech forests. We appreciate the help of Bärbel Angres, Maria Greiner, Stefanie Scheidel and several student assistants in maintaining the incubation experiment and performing analyses in the laboratory.

\section{REFERENCES}

Abramoff, R., Xu, X., Hartman, M., O’Brien, S., Feng, W., Davidson, E., et al. (2017). The Millennial model: in search of measurable pools and transformations for modeling soil carbon in the new century. Biogeochemistry 137, 51-71. doi: 10.1007/s10533-017-0409-7

Albalasmeh, A. A., and Ghezzehei, T. A. (2014). Interplay between soil drying and root exudation in rhizosheath development. Plant Soil 374, 739-751. doi: 10.1007/s11104-013-1910-y

Amézketa, E. (1999). Soil aggregate stability: a review. J. Sustain. Agric. 14, 83-151. doi: 10.1300/J064v14n02_08

Angst, G., Kögel-Knabner, I., Kirfel, K., Hertel, D., and Mueller, C. W. (2016). Spatial distribution and chemical composition of soil organic matter fractions in rhizosphere and non-rhizosphere soil under European beech (Fagus sylvatica L.). Geoderma 264, 179-187. doi: 10.1016/j.geoderma.2015.10.016

Angst, G., Messinger, J., Greiner, M., Häusler, W., Hertel, D., Kirfel, K., et al. (2018). Soil organic carbon stocks in topsoil and subsoil controlled by parent material, carbon input in the rhizosphere, and microbial-derived compounds. Soil Biol. Biochem. 122, 19-30. doi: 10.1016/j.soilbio.2018.03.026

Bailey, V. L., Peacock, A. D., Smith, J. L., and Bolton, H. (2002). Relationships between soil microbial biomass determined by chloroform fumigationextraction, substrate-induced respiration, and phospholipid fatty acid analysis. Soil Biol. Biochem. 34, 1385-1389. doi: 10.1016/S0038-0717(02)00070-6

Banwart, S. A., Bernasconi, S. M., Blum, W. E. H., de Souza, D. M., Chabaux, F., Duffy, C., et al. (2017). Soil functions in Earth's Critical Zone: key results and conclusions. Adv. Agron. 142, 1-27. doi: 10.1016/bs.agron.2016.11.001

Batjes, N. H. (1996). Total carbon and nitrogen in the soils of the world. Eur. J. Soil Sci. 47, 151-163. doi: 10.1111/j.1365-2389.1996.tb01386.x

Bengtson, P., Barker, J., and Grayston, S. J. (2012). Evidence of a strong coupling between root exudation, $\mathrm{C}$ and $\mathrm{N}$ availability, and stimulated SOM decomposition caused by rhizosphere priming effects. Ecol. Evol. 2, 1843-1852. doi: $10.1002 /$ ece 3.311

Blagodatskaya, E., and Kuzyakov, Y. (2008). Mechanisms of real and apparent priming effects and their dependence on soil microbial biomass and community structure: critical review. Biol. Fertil. Soils 45, 115-131. doi: 10.1007/s00374-008-0334-y

Blanco-Canqui, H., and Lal, R. (2004). Mechanisms of carbon sequestration in soil aggregates. CRC. Crit. Rev. Plant Sci. 23, 481-504. doi: 10.1080/07352680490886842

Brzostek, E. R., Greco, A., Drake, J. E., and Finzi, A. C. (2012). Root carbon inputs to the rhizosphere stimulate extracellular enzyme activity and increase nitrogen availability in temperate forest soils. Biogeochemistry 115, 65-76. doi: 10.1007/s10533-012-9818-9

Butler, J. L., Williams, M. A., Bottomley, P. J., and Myrold, D. D. (2003). Microbial community dynamics associated with rhizosphere carbon flow. Appl. Environ. Microbiol. 69, 6793-6800. doi: 10.1128/AEM.69.11.6793-6800.2003

Campbell, E. E., and Paustian, K. (2015). Current developments in soil organic matter modeling and the expansion of model applications: a review. Environ. Res. Lett. 10, 123004-123004. doi: 10.1088/1748-9326/10/12/ 123004

Carminati, A., Moradi, A. B., Vetterlein, D., Vontobel, P., Lehmann, E., Weller, U., et al. (2010). Dynamics of soil water content in the rhizosphere. Plant Soil 332, 163-176. doi: 10.1007/s11104-010-0283-8

Caron, J., Kay, B. D., and Stone, J. A. (1992). Improvement of structural stability of a clay loam with drying. Soil Sci. Soc. Am. J. 56, 1583-1590. doi: 10.2136/sssaj1992.03615995005600050041x

Chabbi, A., Kögel-Knabner, I., and Rumpel, C. (2009). Stabilised carbon in subsoil horizons is located in spatially distinct parts of the soil profile. Soil Biol. Biochem. 41, 256-261. doi: 10.1016/j.soilbio.2008.10.033

\section{SUPPLEMENTARY MATERIAL}

The Supplementary Material for this article can be found online at: https://www.frontiersin.org/articles/10.3389/fenvs. 2018.00140/full\#supplementary-material

Chantigny, M. H., Angers, D. A., Prévost, D., Vézina, L.-P., and Chalifour, F.-P. (1997). Soil aggregation and fungal and bacterial biomass under annual and perennial cropping systems. Soil Sci. Soc. Am. J. 61:262. doi: 10.2136/sssaj1997.03615995006100010037x

Cohen, J. (1988). Statistical Power Analysis for the Behavioral Sciences. New York, NY: Routledge.

Crawford, J. W., Deacon, L., Grinev, D., Harris, J. A., Ritz, K., Singh, B. K., et al. (2012). Microbial diversity affects self-organization of the soil-microbe system with consequences for function. J. R. Soc. Interface 9, 1302-1310. doi: 10.1098/rsif.2011.0679

de Graaff, M.-A., Jastrow, J. D., Gillette, S., Johns, A., and Wullschleger, S. D. (2014). Differential priming of soil carbon driven by soil depth and root impacts on carbon availability. Soil Biol. Biochem. 69, 147-156. doi: 10.1016/j.soilbio.2013.10.047

De Nobili, M., Contin, M., Mondini, C., and Brookes, P. C. (2001). Soil microbial biomass is triggered into activity by trace amounts of substrate. Soil Biol. Biochem. 33, 1163-1170. doi: 10.1016/S0038-0717(01)00020-7

Dijkstra, F. A., Carrillo, Y., Pendall, E., and Morgan, J. A. (2013). Rhizosphere priming: a nutrient perspective. Front. Microbiol. 4:8. doi: 10.3389/fmicb.2013.00216

Drake, J. E., Darby, B. A., Giasson, M. A., Kramer, M. A., Phillips, R. P., and Finzi, A. C. (2013). Stoichiometry constrains microbial response to root exudation- insights from a model and a field experiment in a temperate forest. Biogeosciences 10, 821-838. doi: 10.5194/bg-10-821-2013

Dungait, J. A. J., Hopkins, D. W., Gregory, A. S., and Whitmore, A. P. (2012). Soil organic matter turnover is governed by accessibility not recalcitrance. Glob. Chang. Biol. 18, 1781-1796. doi: 10.1111/j.1365-2486.2012.02665.x

Frostegård, Å., Tunlid, A., and Bååth, E. (1991). Microbial biomass measured as total lipid phosphate in soils of different organic content. J. Microbiol. Methods 14, 151-163. doi: 10.1016/0167-7012(91)90018-L

Frostegård, A., Tunlid, A., and Bååth, E. (2011). Use and misuse of PLFA measurements in soils. Soil Biol. Biochem. 43, 1621-1625. doi: 10.1016/j.soilbio.2010.11.021

Georgiou, K., Abramoff, R. Z., Harte, J., Riley, W. J., and Torn, M. S. (2017). Microbial community-level regulation explains soil carbon responses to long-term litter manipulations. Nat. Commun. 8:1223. doi: 10.1038/s41467-017-01116-z

Georgiou, K., Koven, C. D., Riley, W. J., and Torn, M. S. (2015). Toward improved model structures for analyzing priming: potential pitfalls of using bulk turnover time. Glob. Chang. Biol. 21, 4298-4302. doi: 10.1111/gcb.13039

Glaser, B., Turrión, M. A.-B., and Alef, K. (2004). Amino sugars and muramic acid-biomarkers for soil microbial community structure analysis. Soil Biol. Biochem. 36, 399-407. doi: 10.1016/j.soilbio.2003.10.013

Griffiths, B. S., Ritz, K., Ebblewhite, N., and Dobson, G. (1998). Soil microbial community structure: effects of substrate loading rates. Soil Biol. Biochem. 31, 145-153. doi: 10.1016/S0038-0717(98)00117-5

Hedges, L. V., and Olkin, I. (1985). Statistical Methods for Meta-Analysis. San Diego, CA: Academic Press.

Heinze, S., Ludwig, B., Piepho, H.-P., Mikutta, R., Don, A., Wordell-Dietrich, P. et al. (2018). Factors controlling the variability of organic matter in the top- and subsoil of a sandy Dystric Cambisol under beech forest. Geoderma 311, 37-44. doi: 10.1016/j.geoderma.2017.09.028

Helfrich, M., Ludwig, B., Potthoff, M., and Flessa, H. (2008). Effect of litter quality and soil fungi on macroaggregate dynamics and associated partitioning of litter carbon and nitrogen. Soil Biol. Biochem. 40, 1823-1835. doi: 10.1016/j.soilbio.2008.03.006

Hinsinger, P., Bengough, A. G., Vetterlein, D., and Young, I. M. (2009). Rhizosphere: biophysics, biogeochemistry and ecological relevance. Plant Soil 321, 117-152. doi: 10.1007/s11104-008-9885-9 
Huo, C., Luo, Y., and Cheng, W. (2017). Rhizosphere priming effect: a metaanalysis. Soil Biol. Biochem. 111, 78-84. doi: 10.1016/j.soilbio.2017.04.003

IUSS Working Group (2015). Worl Reference Base for Soil Resources 2014, Update 2015 International Soil Classification System for Naming Soils and Creating Legends for Soil Maps. World Soil Resources Report No. 106. Rome: FAO.

Jobbágy, E. G., and Jackson, R. B. (2000). The vertical distribution of soil organic carbon and its relation to climate and vegetation. Ecol. Appl. 10, 423-436. doi: 10.1890/1051-0761(2000)010[0423:TVDOSO]2.0.CO;2

Jones, D. L., Nguyen, C., and Finlay, R. D. (2009). Carbon flow in the rhizosphere: carbon trading at the soil-root interface. Plant Soil 321, 5-33. doi: 10.1007/s11104-009-9925-0

Kaiser, C., Frank, A., Wild, B., Koranda, M., and Richter, A. (2010). Negligible contribution from roots to soil-borne phospholipid fatty acid fungal biomarkers 18:2omega6,9 and 18:1omega9. Soil Biol. Biochem. 42, 1650-1652. doi: 10.1016/j.soilbio.2010.05.019

Karhu, K., Hilasvuori, E., Fritze, H., Biasi, C., Nykänen, H., Liski, J., et al. (2016). Priming effect increases with depth in a boreal forest soil. Soil Biol. Biochem. 99, 104-107. doi: 10.1016/j.soilbio.2016.05.001

Keidel, L., Lenhart, K., Moser, G., and Müller, C. (2018). Depth-dependent response of soil aggregates and soil organic carbon content to long-term elevated CO 2 in a temperate grassland soil. Soil Biol. Biochem. 123, 145-154. doi: 10.1016/j.soilbio.2018.05.005

Keiluweit, M., Bougoure, J. J., Nico, P. S., Pett-Ridge, J., Weber, P. K., and Kleber, M. (2015). Mineral protection of soil carbon counteracted by root exudates. Nat. Clim. Chang. 5, 588-595. doi: 10.1038/nclimate2580

Kramer, S., Marhan, S., Haslwimmer, H., Ruess, L., and Kandeler, E. (2013). Temporal variation in surface and subsoil abundance and function of the soil microbial community in an arable soil. Soil Biol. Biochem. 61, 76-85. doi: 10.1016/j.soilbio.2013.02.006

Kuzyakov, Y. (2010). Priming effects: interactions between living and dead organic matter. Soil Biol. Biochem. 42, 1363-1371. doi: 10.1016/j.soilbio.2010.04.003

Kuzyakov, Y., Friedel, J. K., and Stahr, K. (2000). Review of mechanisms and quantification of priming effects. Soil Biol. Biochem. 32, 1485-1498. doi: 10.1016/S0038-0717(00)00084-5

Kuzyakov, Y., Hill, P. W., and Jones, D. L. (2006). Root exudate components change litter decomposition in a simulated rhizosphere depending on temperature. Plant Soil 290, 293-305. doi: 10.1007/s11104-006-9162-8

Lal, R. (2016). Beyond COP 21: potential and challenges of the "4 per Thousand" initiative. J. Soil Water Conserv. 71, 20A-25A. doi: 10.2489/jswc.71.1.20A

Lal, R., Delgado, J. A., Groffman, P. M., Millar, N., Dell, C., and Rotz, A. (2011). Management to mitigate and adapt to climate change. J. Soil Water Conserv. 66, 276-285. doi: 10.2489/jswc.66.4.276

Lehmann, A., Zheng, W., and Rillig, M. C. (2017). Soil biota contributions to soil aggregation. Nat. Ecol. Evol. 1, 1828-1835. doi: 10.1038/s41559-017-0344-y

Lorenz, K., and Lal, R. (2005). The depth distribution of soil organic carbon in relation to land use and management and the potential of carbon sequestration in subsoil horizons. Adv. Agron. 88, 35-66. doi: 10.1016/S0065-2113(05)88002-2

Luo, Y., Zhao, X., Andrén, O., Zhu, Y., and Huang, W. (2014). Artificial root exudates and soil organic carbon mineralization in a degraded sandy grassland in northern China. J. Arid Land 6, 423-431. doi: 10.1007/s40333-0140063-z

Marx, M., Buegger, F., Gattinger, A., Zsolnay, Á., and Charles Munch, J. (2010). Determination of the fate of regularly applied13C-labeled-artificialexudates C in two agricultural soils. J. Plant Nutr. Soil Sci. 173, 80-87. doi: $10.1002 /$ jpln.200800104

Meier, I. C., Finzi, A. C., and Phillips, R. P. (2017). Root exudates increase N availability by stimulating microbial turnover of fast-cycling N pools. Soil Biol. Biochem. 106, 119-128. doi: 10.1016/j.soilbio.2016.12.004

Minasny, B., Malone, B. P., McBratney, A. B., Angers, D. A., Arrouays, D., Chambers, A., et al. (2017). Soil carbon 4 per mille. Geoderma 292, 59-86. doi: 10.1016/j.geoderma.2017.01.002

Mondini, C., Cayuela, M. L., Sanchez-Monedero, M. A., Roig, A., and Brookes, P. C. (2006). Soil microbial biomass activation by trace amounts of readily available substrate. Biol. Fertil. Soils 42, 542-549. doi: 10.1007/s00374-005-0049-2

Moni, C., Rumpel, C., Virto, I., Chabbi, A., and Chenu, C. (2010). Relative importance of sorption versus aggregation for organic matter storage in subsoil horizons of two contrasting soils. Eur. J. Soil Sci. 61, 958-969. doi: 10.1111/j.1365-2389.2010.01307.x

Nelder, J. A., and Mead, R. (1965). A simplex method for function minimization. Comput. J. 7, 308-313. doi: 10.1093/comjnl/7.4.308

Oades, J. M. (1984). Soil organic matter and structural stability: mechanisms and implications for management. Plant Soil 76, 319-337. doi: 10.1007/BF02205590

Oades, J. M., and Waters, A. G. (1991). Aggregate hierarchy in soils. Austr. J. Soil Res. 29:815. doi: 10.1071/SR9910815

Paterson, E., and Sim, A. (2013). Soil-specific response functions of organic matter mineralization to the availability of labile carbon. Glob. Chang. Biol. 19, 1562-1571. doi: 10.1111/gcb.12140

Phillips, D. A., Fox, T. C., and Six, J. (2006). Root exudation (net efflux of amino acids) may increase rhizodeposition under elevated CO2. Glob. Chang. Biol. 12, 561-567. doi: 10.1111/j.1365-2486.2006.01100.x

Powlson, D. S., Whitmore, A. P., and Goulding, K. W. T. (2011). Soil carbon sequestration to mitigate climate change: a critical reexamination to identify the true and the false. Eur. J. Soil Sci. 62, 42-55. doi: 10.1111/j.1365-2389.2010.01342.x

Puget, P., Angers, D. A., and Chenu, C. (1999). Nature of carbohydrates associated with water-stable aggregates of two cultivated soils. Soil Biol. Biochem. 31, 55-63. doi: 10.1016/S0038-0717(98)00103-5

Rasmussen, C., Torn, M. S., and Southard, R. J. (2005). Mineral assemblage and aggregates control carbon dynamics in a california conifer forest. Soil Sci. Soc. Am. J. 69:6. doi: 10.2136/sssaj2005.0040

Rasse, D. P., Rumpel, C., and Dignac, M.-F. (2005). Is soil carbon mostly root carbon? Mechanisms for a specific stabilisation. Plant Soil 269, 341-356. doi: 10.1007/s11104-004-0907-y

Rumpel, C., Chabbi, A., and Marschner, B. (2012). "Carbon storage and sequestration in subsoil horizons: knowledge, gaps and potentials," in Recarbonization of the Biosphere, eds R. Lal, K. Lorenz, R. Hüttl, B. Schneider, and J. von Braun (Dordrecht: Springer).

Rumpel, C., and Kögel-Knabner, I. (2011). Deep soil organic matter-a key but poorly understood component of terrestrial C cycle. Plant Soil 338, 143-158. doi: 10.1007/s11104-010-0391-5

Salomé, C., Nunan, N., Pouteau, V., Lerch, T. Z., and Chenu, C. (2010). Carbon dynamics in topsoil and in subsoil may be controlled by different regulatory mechanisms. Glob. Chang. Biol. 16, 416-426. doi: 10.1111/j.1365-2486.2009.01884.x

Sanaullah, M., Chabbi, A., Leifeld, J., Bardoux, G., Billou, D., and Rumpel, C. (2010). Decomposition and stabilization of root litter in top- and subsoil horizons: what is the difference? Plant Soil 338, 127-141. doi: 10.1007/s11104-010-0554-4

Schrumpf, M., Kaiser, K., Guggenberger, G., Persson, T., Kögel-Knabner, I., and Schulze, E. D. (2013). Storage and stability of organic carbon in soils as related to depth, occlusion within aggregates, and attachment to minerals. Biogeosciences 10, 1675-1691. doi: 10.5194/bg-10-1675-2013

Segoli, M., De Gryze, S., Dou, F., Lee, J., Post, W. M., Denef, K., et al. (2013). AggModel: a soil organic matter model with measurable pools for use in incubation studies. Ecol. Modell. 263, 1-9. doi: 10.1016/j.ecolmodel.2013.04.010

Shen, Y., Ström, L., Jönsson, J.-̊., and Tyler, G. (1996). Low-molecular organic acids in the rhizosphere soil solution of beech forest (Fagus sylvatica L.) cambisols determined by ion chromatography using supported liquid membrane enrichment technique. Soil Biol. Biochem. 28, 1163-1169. doi: 10.1016/0038-0717(96)00119-8

Smith, W. H. (1970). Root exudates of seedling and mature sugar maple. Phytopathology 60, 701-703. doi: 10.1094/Phyto-60-701

Smith, W. H. (1976). Character and significance of forest tree root exudates. Ecology 57, 324-331. doi: 10.2307/1934820

Stamati, F. E., Nikolaidis, N. P., Banwart, S., and Blum, W. E. H. (2013). A coupled carbon, aggregation, and structure turnover (CAST) model for topsoils. Geoderma 211-212, 51-64. doi: 10.1016/j.geoderma.2013.06.014

Steinauer, K., Chatzinotas, A., and Eisenhauer, N. (2016). Root exudate cocktails: the link between plant diversity and soil microorganisms? Ecol. Evol. 6, 7387-7396. doi: 10.1002/ece3.2454

Stockmann, U., Adams, M. A., Crawford, J. W., Field, D. J., Henakaarchchi, N., Jenkins, M., et al. (2013). The knowns, known unknowns and unknowns of sequestration of soil organic carbon. Agric. Ecosyst. Environ. 164, 80-99. doi: 10.1016/j.agee.2012.10.001 
Tian, J., Pausch, J., Yu, G., Blagodatskaya, E., and Kuzyakov, Y. (2016). Aggregate size and glucose level affect priming sources: a three-sourcepartitioning study. Soil Biol. Biochem. 97, 199-210. doi: 10.1016/j.soilbio.2016. 03.013

Tisdall, J. M., and Oades, J. M. (1982). Organic matter and water-stable aggregates in soils. J. Soil Sci. 33, 141-163. doi: 10.1111/j.1365-2389.1982.tb01755.x

Totsche, K. U., Amelung, W., Gerzabek, M. H., Guggenberger, G., Klumpp, E., Knief, C., et al. (2018). Microaggregates in soils. J. Plant Nutr. Soil Sci. 181, 104-136. doi: 10.1002/jpln.201600451

Traoré, O., Groleau-Renaud, V., Plantureux, S., Tubeileh, A., and BoeufTremblay, V. (2000). Effect of root mucilage and modelled root exudates on soil structure. Eur. J. Soil Sci. 51, 575-581. doi: 10.1046/j.1365-2389.2000. 00348.x

Tückmantel, T., Leuschner, C., Preusser, S., Kandeler, E., Angst, G., Mueller, C. W., et al. (2017). Root exudation patterns in a beech forest: dependence on soil depth, root morphology, and environment. Soil Biol. Biochem. 107, 188-197. doi: 10.1016/j.soilbio.2017.01.006

Van Groenigen, K.-J., Six, J., Harris, D., and Van Kessel, C. (2007). Elevated $\mathrm{CO} 2$ does not favor a fungal decomposition pathway. Soil Biol. Biochem. 39, 2168-2172. doi: 10.1016/j.soilbio.2007.03.009

van Hees, P. A. W., Jones, D. L., Finlay, R., Godbold, D. L., and Lundström, U. S. (2005). The carbon we do not see-the impact of low molecular weight compounds on carbon dynamics and respiration in forest soils: a review. Soil Biol. Biochem. 37, 1-13. doi: 10.1016/j.soilbio.2004.06.010

Vasilyeva, N. A., Ingtem, J. G., and Silaev, D. A. (2016). Nonlinear dynamical model of microorganism growth in soil. Comput. Math. Model. 27, 172-180. doi: 10.1007/s10598-016-9312-7 von Lützow, M., Kogel-Knabner, I., Ekschmitt, K., Matzner, E., Guggenberger, G., Marschner, B., et al. (2006). Stabilization of organic matter in temperate soils: mechanisms and their relevance under different soil conditions a review. Eur. J. Soil Sci. 57, 426-445. doi: 10.1111/j.1365-2389.2006. 00809.x

Wang, H., Xu, W., Hu, G., Dai, W., Jiang, P., and Bai, E. (2015). The priming effect of soluble carbon inputs in organic and mineral soils from a temperate forest. Oecologia 178, 1239-1250. doi: 10.1007/s00442-015-3290-x

Willers, C., Jansen van Rensburg, P. J., and Claassens, S. (2015). Phospholipid fatty acid profiling of microbial communities-a review of interpretations and recent applications. J. Appl. Microbiol. 119, 1207-1218. doi: 10.1111/jam.12902

Zhang, X., and Amelung, W. (1996). Gas chromatographic determination of muramic acid, glucosamine, mannosamine, and galactosamine in soils. Soil Biol. Biochem. 28, 1201-1206. doi: 10.1016/0038-0717(96) 00117-4

Conflict of Interest Statement: The authors declare that the research was conducted in the absence of any commercial or financial relationships that could be construed as a potential conflict of interest.

Copyright (ㄷ) 2018 Baumert, Vasilyeva, Vladimirov, Meier, Kögel-Knabner and Mueller. This is an open-access article distributed under the terms of the Creative Commons Attribution License (CC BY). The use, distribution or reproduction in other forums is permitted, provided the original author(s) and the copyright owner(s) are credited and that the original publication in this journal is cited, in accordance with accepted academic practice. No use, distribution or reproduction is permitted which does not comply with these terms. 